\title{
Valores de producción de semillas y hojarasca de diferentes especies del tipo forestal siempreverde de la Cordillera de la Costa de Valdivia obtenidos durante un período de 10 años
}

A ten year study of seed and litter production of different tree species of the broadleaved evergreen forests of the Coastal Cordillera of Valdivia

C.D.O.: $232.311-1,568$

Claudio Donoso, Marcelo Hernández y Celso Navarro

Instituto de Silvicultura, Facultad de Ciencias Forestales Universidad Austral de Chile, Casilla 567, Valdivia, Chile.

\section{SUMMARY}

Data of 10 years of seed and litter production in evergreen forests of the Coastal Mountains of Valdivia with and without application of silvicultural treatments are analized. Data were collected monthly from $0,1 \mathrm{~m}^{2}$ boxes randomly placed on each of 1 hectare plots in three test plots, tree plots submitted to clear-cut, three plots under seed-tree treatment and two plots under shelterwood treatment.

Monthly and seasonal tendencies of seed production and viability are determined for Laurelia philippiana, Saxegothaea conspicua, Amomyrtus luma, A. meli, Eucryphia cordifolia, Aextoxicon punctatum, Podocarpus nubigena, Gevuina avellana and Drimys winteri. Average litter production and monthly variation is also determined. Finally annual variation of seed production in ten years for all the species is analized.

Only Aextoxicon punctatum shows a definite periodicity. The other species, require more years of study to clarify their tendencies.

\section{RESUMEN}

Se presenta información de producción de semillas y hojarasca, viabilidad de semillas y periodicidad de la producción de bosques siempreverdes de la ladera occidental de la Cordillera de la Costa de Valdivia, sin y con intervención silvicultural registrada durante 10 años. Las recolecciones se efectuaron mensualmente en tres parcelas testigo, en tres parcelas cortadas a tala rasa, en tres parcelas taladas en que se dejaron 10 a 12 árboles semilleros y en dos parcelas intervenidas mediante método de protección uniforme. Las parcelas eran de 1 hectárea cada una y la recolección se efectuó en cajones de $0.1 \mathrm{~m}^{2}$ de superficie cada uno, distribuidos regularmente al azar en cada parcela.

Se determinan las tendencias mensuales y estacionales de la producción de semillas, así como su viabilidad, para las especies Laurelia philippiana, Saxegothaea conspicua, Amomyrtus luma, Eucryphia cordifolia, Aextoxicon punctatum, Podocarpus nubigena, A. meli, Gevuina avellana y Drimys winteri, tanto en los bosques intervenidos como no intervenidos. Se determina también la producción anual de materia seca en estos bosques y su variación mensual. Finalmente se analiza la variación anual de la producción de semillas en 10 años, encontrándose sólo una periodicidad definida en A. punctatum y ciertas tendencias que requieren de más años de información para definirse en las demás especies.

\section{INTRODUCCION}

Si se quiere hacer silvicultura en cualquier tipo de bosque es necesario tener el conocimiento mínimo de la autoecología de todas las especies componentes, para a través de ella ser capaces de inter- pretar la estructura y la dinámica del bosque. De esa manera será posible actuar sobre la estructura del bosque para acelerar los procesos dinámicos naturales o para modificarla mediante la aplicación de las técnicas silviculturales que correspondan. 
El primer eslabón de la cadena de procesos silviculturales (Baker, 1980) es el abastecimiento adecuado de las semillas de las especies que interesen y también de las que no interesen, porque son eventuales competidoras a las que hay que conocer. Los procesos de producción de semillas que el silvicultor necesita conocer son los relacionados con la floración, fructificación, diseminación y la periodicidad de la producción, viabilidad y germinación de ellas. El conocimiento de la mayor parte de esta información sólo puede obtenerse de la observación en el tiempo, de la investigación y experimentación.

La obtención de este conocimiento es más complicada y de largo plazo, en la medida que los bosques son más complejos en cuanto a la composición de especies y a la variación existente en ellas. Sin duda, el tipo forestal siempreverde es el más complejo y variable de los tipos forestales chilenos. Cada una de las numerosas especies constituyentes de estos bosques presentará modelos diferentes de floración, fructificación, diseminación y germinación, que, además, podrán variar también en función de los cambios de hábitat que se produzcan en su distribución. Sin este conocimiento básico perteneciente a la ecología de la regeneración de estas especies no es posible realizar ninguna silvicultura bien sustentada (Donoso, 1993b). También puede ser importante su conocimiento para el manejo de la fauna silvestre existente en estos bosques, porque buena parte de ella encuentra alimento en los frutos y semillas de estas especies (Armesto et al., 1987). Para obtener este tipo de información se inició en 1982 un proyecto de investigación que cumple pronto 12 años y que requiere aún de muchos años más para obtener una información plenamente confiable (Daniel et al., 1982). Este proyecto se realiza en los bosques siempreverdes costero y andino, en los bosques de Alerce costeros y andinos y en renovales de Canelo. Los resultados han sido entregados en informes técnicos anuales y ya fue publicado un trabajo científico en relación con el bosque de Alerce costero (Donoso, 1993a).

La información general sobre este tipo de conocimiento se puede encontrar en Baker 1950, Kozlowski 1971, U.S.D.A. Forest Service 1974, Krugman et al., 1974 y Daniel et al., 1982.

Antecedentes publicados sobre el tema en bosques y especies chilenos se encuentran en Riveros y Alberdi (1978) y Murúa y González (1985) para bosques transicionales de Roble Laurel-Lingue a siempreverde dominados por Aextoxicon punctatum, en Burschel et al. (1976), Puente (1980), Becker (1981) y Mascareño (1987) para bosques dominados por distintas especies de Nothofagus, y en Donoso (1993a) para bosques de Alerce costero.

Los objetivos de este trabajo se desprenden de lo señalado en la introducción y consisten en destacar los valores, patrones y tendencias en los fenómenos relacionados con la producción de semillas y hojarasca obtenidos en un período de 10 años:

1. Obtener la información sobre los patrones de caída de semillas de cada una de las especies analizadas y su variación intraanual e interanual.

2. Obtener la información preliminar sobre los posibles ciclos o tendencias de producción de semillas que pudieran encontrarse en las diferentes especies.

4. Obtener los valores de producción de materia seca para el tipo forestal siempreverde costero.

5. Obtener antecedentes relacionados con fenómenos de semillación en bosques intervenidos mediante distintos métodos silviculturales en el tipo forestal siempreverde.

\section{AREA DE ESTUDIO}

El área de estudio se ubica en la ladera occidental de la Cordillera de la Costa de Valdivia en bosques del tipo forestal siempreverde (Donoso, 1981) a $40^{\circ}$ lat. sur, altitud de 550 a $680 \mathrm{~m}$, que representa las mayores altitudes del tipo forestal en este sector (Donoso, 1990). Por encima de estas altitudes se produce la transición hacia el tipo forestal Alerce (fig. 1)

La topografía es quebrada, con sectores con fuertes pendientes. El material original es de origen metamórfico, formado por rocas del Paleozoico y Precámbrico (Ruiz, 1965). Sobre estas rocas micaesquísticas se desarrollan suelos de profundidades medianas, que se hacen muy delgados en cumbres de sectores planos. El clima general es del tipo templado cálido de costa occidental (Fuenzalida, 1950), con temperaturas moderadas y altas precipitaciones distribuidas a lo largo de todo el año, pero con un período seco que es corto y variable en su distribución durante el verano (fig. 2).

En el área de estudio se han registrado precipitaciones de $4.000 \mathrm{~mm}$ anuales (Gutiérrez, 1984). 


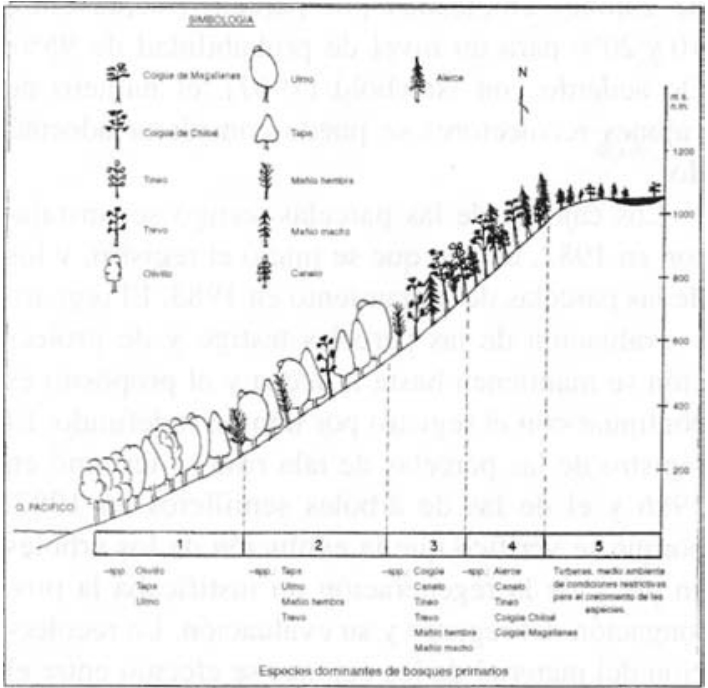

Figura 1. Perfil transversal mostrando la distribución altitudinal de las especies componentes del tipo forestal siempreverde en la vertiende occidental de la Cordillera de la Costa de Valdivia, en un continuum vegetacional.

Altitudinal profile in the western slope of the Coastal Cordillera of Valdivia, showing the vegetation continuum.

La vegetación arbórea está constituida por varias especies que se señalan en el cuadro 1 en conjunto con los parámetros dasométricos que muestran la estructura del bosque. Dicha estructu- ra se complementa con el plano de distribución horizontal, que indica un bosque multiespecífico, irregular (fig. 3).

\section{CUADRO 1}

Tabla de rodal del bosque siempreverde del área de ensayo

Stand table of the evergreen forest studied

\begin{tabular}{|c|c|c|c|}
\hline Especie & $\begin{array}{c}\mathrm{N}^{\circ} \\
\text { árboles } \\
\text { por ha }\end{array}$ & $\begin{array}{c}\text { Area } \\
\text { basal } \\
\text { por ha } \\
\left(\mathrm{m}^{2}\right)\end{array}$ & $\begin{array}{c}\text { Volumet } \\
\text { bruto } \\
\text { por ha } \\
\left(\mathrm{m}^{3}\right)\end{array}$ \\
\hline Laurelia philippiana & 170 & 22.5 & 113.1 \\
\hline Saxegothaea conspicua & 112 & 21.8 & 67.9 \\
\hline Amomyrtus luma & 190 & 13.5 & 31.9 \\
\hline Dasyphyllum diacanthoides & 43 & 13.1 & 44.5 \\
\hline Eucryphia cordifolia & 28 & 12.9 & 79.9 \\
\hline Aextoxicon punctatum & 21 & 3.1 & 14.4 \\
\hline Podocarpus nubigena & 44 & 2.6 & 9.5 \\
\hline Amomyrtus meli & 31 & 2.6 & 14.5 \\
\hline Weinmannia trichosperma & 5 & 2.2 & 27.0 \\
\hline Gevuina avellana & 55 & 1.9 & 5.5 \\
\hline Drimys winteri & 25 & 1.6 & 26.0 \\
\hline Otras (especies menores) & 131 & 3.8 & 1.1 \\
\hline Total & 684 & 101.6 & 435.3 \\
\hline
\end{tabular}

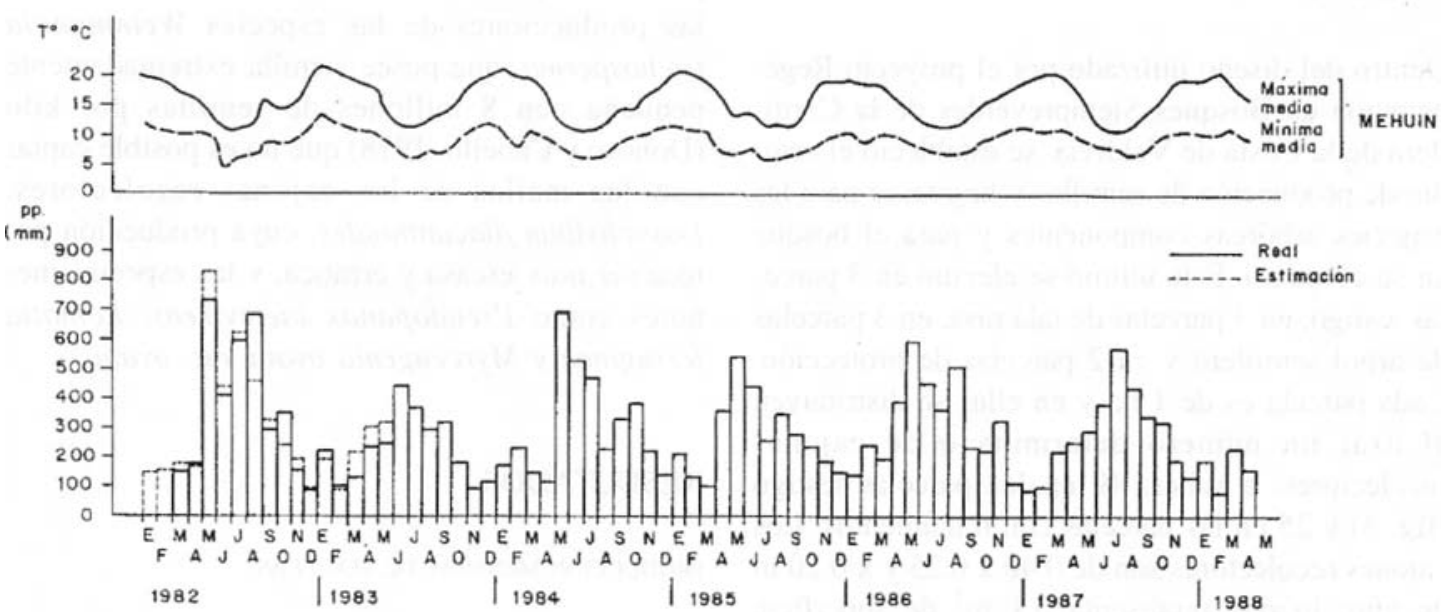

Figura 2. Promedio mensual de la temperatura y precipitación durante el periodo de estudio en la Cordillera de la Costa de Valdivia. La precipitación está calculada sobre la base de un registro de un año (1982-83) a $600 \mathrm{~m}$ de altitud y registros posteriores en la Estación Punahue que mostraron la mejor correlación con el registro base del lugar.

Average temperature and rainfall during the period of study in the Coastal Range of Valdivia. Precipitation was estimated from one year record $(1982-83)$ at $600 \mathrm{~m}$, and subsequently from a correlation with records from Punahue at lower altitudes. 


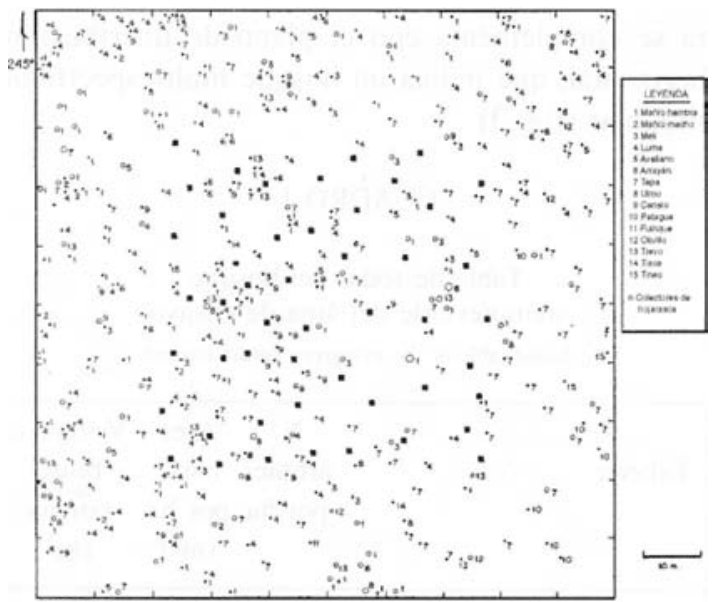

Figura 3. Plano de distribución horizontal de los árboles de una parcela de 1 ha en un bosque siempreverde costero, indicando la ubicación de los cajones recolectores de hojarasca.

Stem distribution pattern within a $\mathbf{1}$ ha plot in an evergreen forest of the Coastal Range, showing the position of the litter and seed colectors.

E1 sotobosque consta de 10 a 15 especies arbustivas entre las que destacan Chusquea macrostachya, Pseudopanax laetevirens, Rhaphithamnus spinosus, Myrceugenia planipes y Azara lanceolata, algunas enredaderas o lianas y varias especies de helechos y musgos.

\section{METODO}

Dentro del diseño utilizado por el proyecto Regeneración en Bosques Siempreverdes de la Cordillera de la Costa de Valdivia, se estableció el estudio de producción de semillas y hojarasca para las especies arbóreas componentes y para el bosque en su conjunto. Este último se efectuó en 3 parcelas testigo, en 3 parcelas de tala rasa, en 3 parcelas de árbol semillero y en 2 parcelas de protección. Cada parcela es de 1 ha y en ellas se distribuyen al azar un número determinado de cajones recolectores, a saber, 49 en las parcelas testigo (fig. 3) y 25 en las parcelas con tratamientos. Los cajones recolectores son de 0.40 x 0.25 y x $0.20 \mathrm{~m}$ de alto, lo que representa $0.1 \mathrm{~m}^{2}$ de superficie recolectora por cajón. La superficie está cubierta con una malla plástica fina, con agujeros de aproximadamente $1 \mathrm{~mm}^{2}$. Los cajones van instalados en 4 patas para evitar el contacto de la malla con el piso y son numerados dentro de cada parcela.

El error estándar de muestreo con los números de cajones empleados por parcela fluctúa entre 10 y $20 \%$ para un nivel de probabilidad de $95 \%$. De acuerdo con Newbold (1967), el número de cajones recolectores se puede considerar adecuado.

Los cajones de las parcelas testigo se instalaron en 1982, año en que se inició el registro, y los de las parcelas de tratamiento en 1983. El registro y evaluación de las parcelas testigo y de protección se mantienen hasta la fecha y el propósito es continuar con el registro por tiempo indefinido. El registro de las parcelas de tala rasa se terminó en 1986 y el de las de árboles semilleros en 1987, porque se verificó que la evolución de los árboles en pie y de la regeneración no justificaba la prolongación del registro y su evaluación. La recolección del material de los cajones se efectuó entre el primer y tercer día de cada mes. El material se separó en hojarasca y semillas en el laboratorio; estas últimas se identificaron y se contaron. Luego se secaron en un horno a $105^{\circ} \mathrm{C}$ durante 24 horas para posteriormente pesarlas.

A partir de 1986 se aplicó todos los meses, a todos los semilleros, una prueba de corte cuyo objetivo es estimar la viabilidad (Hartmann y Kester, 1975).

Las especies analizadas en cuanto a producción de semillas fueron Laurelia philippiana, Eucryphia cordifolia, Drimys winteri, Saxegothaea conspicua, Amomyrtus luma, Amomyrtus meli, Aextoxicon punctatum y Gevuina avellana. No se evaluaron las producciones de las especies Weinmannia trichosperma, que posee semilla extremadamente pequeña con 8 millones de semillas por kilo (Donoso y Cabello, 1978) que no es posible captar con las mallas de los cajones recolectores, Dasyphyllum diacanthoides, cuya producción parece ser muy escasa y errática, y las especies menores como Pseudopanax laetevirens, Lomatia ferruginea y Myrceugenia ovata var. ovata.

\section{RESULTADOS}

PRODUCCION MENSUAL DE SEMILLAS

\section{- En bosques no intervenidos de la Cordillera de la Costa de Valdivia}

La producción mensual de semillas durante 10 períodos consecutivos ( 1 período $=12$ meses) de las especies analizadas se presenta en los cuadros 2 al 10. Se puede verificar que existe una gran 


\section{CUADRO 2}

Producción mensual de semillas de Laurelia philippiana en la Cordillera de la Costa de Valdivia en el período de 10 años. Entre paréntesis, valores de producción de las parcelas bajo el método de protección Monthly production of $L$. philippiana seeds in the Coastal Mountains of Valdivia in a 10 years period

Production values of the shelterwood plots in parenthesis

\begin{tabular}{|c|c|c|c|c|c|c|c|c|c|c|c|c|}
\hline \multirow[b]{3}{*}{ MES } & \multicolumn{10}{|c|}{ Miles de semillas por hectárea } & \multirow{2}{*}{\multicolumn{2}{|c|}{$\begin{array}{c}\text { Promedios mensuales } \\
\text { (+/- D.E.) }\end{array}$}} \\
\hline & \multicolumn{10}{|c|}{ Período } & & \\
\hline & $1982-83$ & $1983-84$ & $1984-85$ & $1985-86$ & $1986-87$ & $1987-88$ & $1988-89$ & $1989-90$ & $1990-91$ & 1991-92 & & \\
\hline febrero & SI & 269.4 & 192.5 & 811.6 & 79.6 & 1097.3 & 270.1 & 72.8 & 264.6 & 15.6 & $307.4+/-$ & 367.0 \\
\hline marzo & 358.5 & 255.7 & 407.4 & 572.2 & 518.4 & 544.9 & 314.8 & 71.4 & 2861.2 & 241.5 & $614.6+/-$ & 804.5 \\
\hline abril & 2107.5 & 1567.3 & 1510.5 & 7870.8 & 724.5 & 3269.4 & 831.3 & 1336.1 & 3240.8 & 278.9 & $22737+/-$ & 1031.0 \\
\hline mayo & 1295.9 & 1087.1 & 479.5 & 1410.2 & 841.5 & 5138.8 & 116.5 & 1868.9 & 4912.9 & 180.9 & $1733.2+/-$ & 1788.9 \\
\hline junio & 1248.3 & 985.6 & 306.8 & 1599.9 & 578.9 & 1182.9 & 155.1 & 1629.3 & 4231.9 & 78.2 & $1199.7+/-$ & 1207.4 \\
\hline julio & 4017 & 287.1 & 94.6 & 358.5 & 186.4 & 1829.9 & 14.2 & 135.1 & 167.8 & 37.4 & $351.3+/-$ & 672.8 \\
\hline agosto & 223.8 & 129.2 & 240.6 & 2367 & 148.3 & 1959.2 & 60.1 & 414.6 & 1143.5 & 80.3 & $463.6+/-$ & 612.9 \\
\hline septiembre & 104.8 & 55.7 & 6.9 & 169.4 & 47.6 & 500.7 & 151.6 & 140.2 & 694.5 & 25.8 & $189.7+/-$ & 226.4 \\
\hline octubre & 37.4 & 148.9 & 17.5 & 29.2 & 55.1 & 661.6 & 3.4 & 21.8 & 290.4 & 0.0 & $126.5+/-$ & 208.2 \\
\hline noviembre & 108.7 & 104.1 & 19.9 & 87.8 & 23.2 & 121.8 & 7.7 & 10.2 & 29.8 & 7.5 & $52.1+/-$ & 47.3 \\
\hline diciembre & 85.7 & 68.7 & 37.4 & 78.9 & 25.2 & 217.7 & 173.1 & 65.3 & 14.9 & 2.7 & $77.0+/-$ & 69.1 \\
\hline enero & 92.8 & 108.1 & 170.8 & 29.3 & 12.2 & 132.0 & 173.5 & 240.8 & 77.5 & 680.0 & $171.7+/-$ & 77.7 \\
\hline TOTAL & 6065.1 & 5066.9 & 3484.4 & 13254.5 & 3240.9 & 16656.2 & 2271.4 & 6006.5 & 17929.8 & 1628.8 & $7560.5+/-$ & 7113.2 \\
\hline & (2028.5) & (1319.0) & ,12280.9) & (8473.2) & (9057.5) & (6778.9) & $(6150.1)$ & (13366.0) & $(6150.1)$ & (1012.0) & $(6718.5)+/-$ & (4578.7) \\
\hline
\end{tabular}

SI- sin información

variación tanto intraanual como interanual en la producción de semillas por hectárea de todas las especies durante los 10 años de evaluación. Aun cuando la variación de la producción mensual es alta, como lo señalan las desviaciones estándar de los promedios mensuales de 10 años para todas las especies, la caída de semillas tiene una tendencia estacional que es característica de cada especie y se registra año a año con pequeñas variaciones (fig. 4a), b), c), d), e), f), g), h), e i).

L. philippiana inicia normalmente la diseminación de sus semillas en febrero y marzo (cuadro 2 y fig. 4a). La caída masiva de las semillas, a nivel del rodal, se produce en los meses de abril, mayo y junio (fig 4a), normalmente en los dos primeros y rara vez en junio (cuadro 2). A partir del mes de julio la caída de las semillas disminuye gradual pero claramente, hasta el inicio de la producción del período siguiente (fig. 4a).

Saxegothaea conspicua inicia la caída de las semillas y, simultáneamente, alcanza su máximo durante el mes de enero (fig. 4b, cuadro 3). Hay una caída importante todavía en febrero, y luego disminuye fuertemente en el resto de los meses del año (fig. 4b y cuadro 3).

Amomyrtus luma inicia la caída de sus semillas en enero, luego presenta un máximo en febrero, una caída importante que continúa en marzo, y una clara y consistente disminución a partir de abril y hasta diciembre (fig. 4c), mes en que durante algunos años puede haber un suave inicio de la caída (cuadro 4). Lo normal es que el máximo se produzca en febrero, pero puede desplazarse a veces a marzo (período 1984) e incluso a enero (período 1989) (cuadro 4).

Generalmente la caída de semillas de Eucryphia cordifolia se inicia con altos valores en abril (fig. 4d), aunque hay períodos en que puede haberse iniciado en marzo, como el período 1984-85 o el 86-87 (cuadro 5). La mayor caída ocurre en mayo generalmente (fig. 4d), pero en algunos años puede ocurrir también en abril o en junio (cuadro 5). A partir del mes de julio la caída de semillas prosigue pero totalmente reducida y disminuyendo gradualmente, hasta llegar a 0 en algunos meses en distintos años (fig. 4d, cuadro 5). 
Fig. $4 \mathrm{a}$
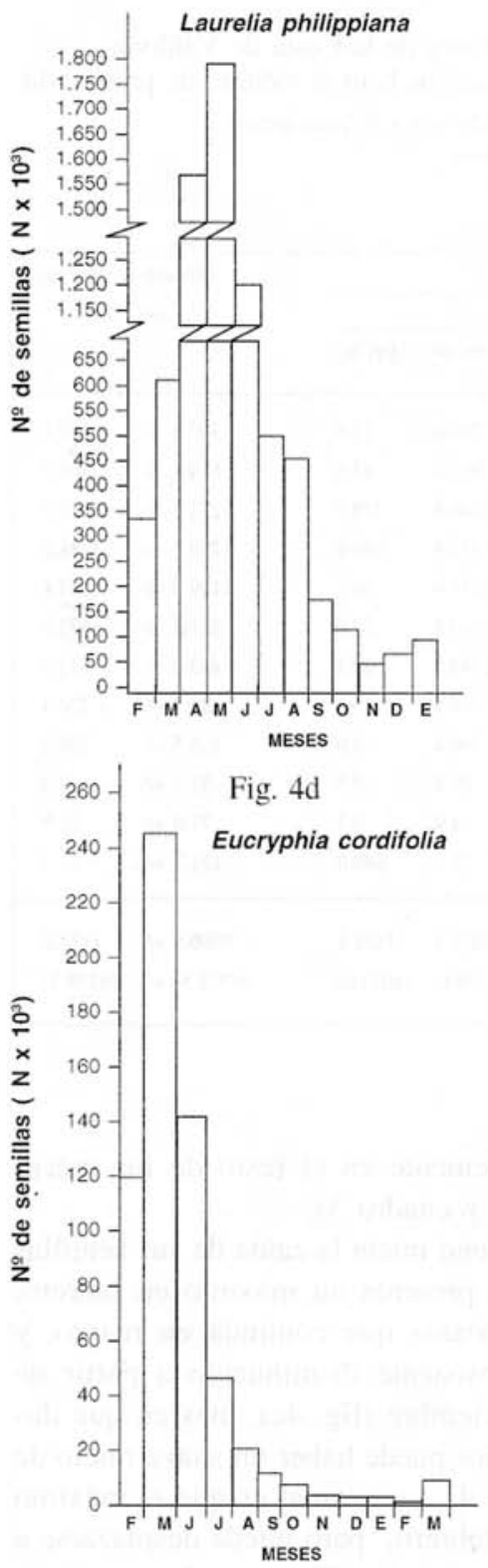

Fig. $4 \mathrm{~b}$

Saxegothaea conspicua

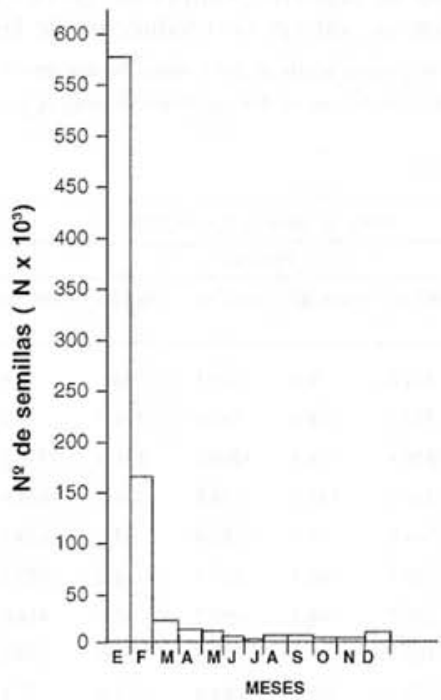

Fig. $4 \mathrm{e}$

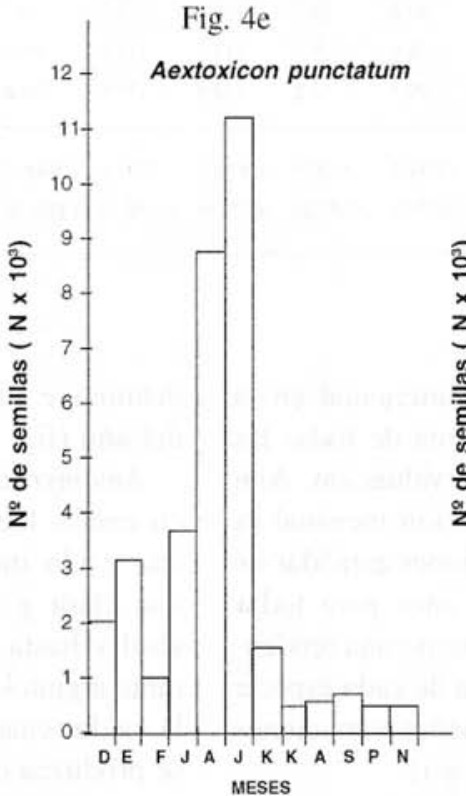

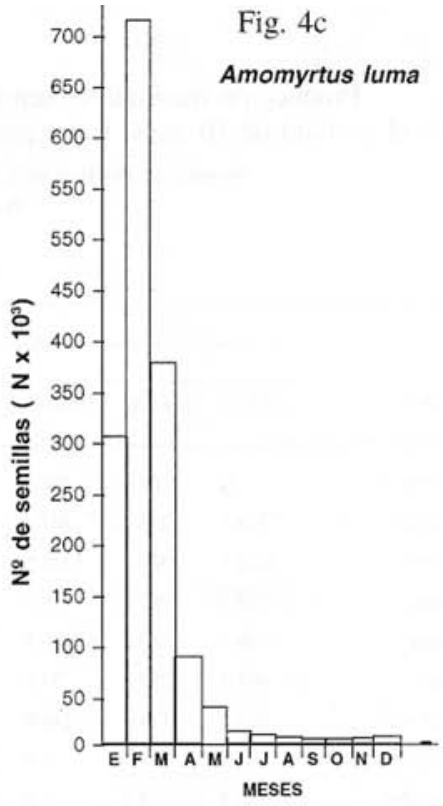

Fig. $4 \mathrm{f}$

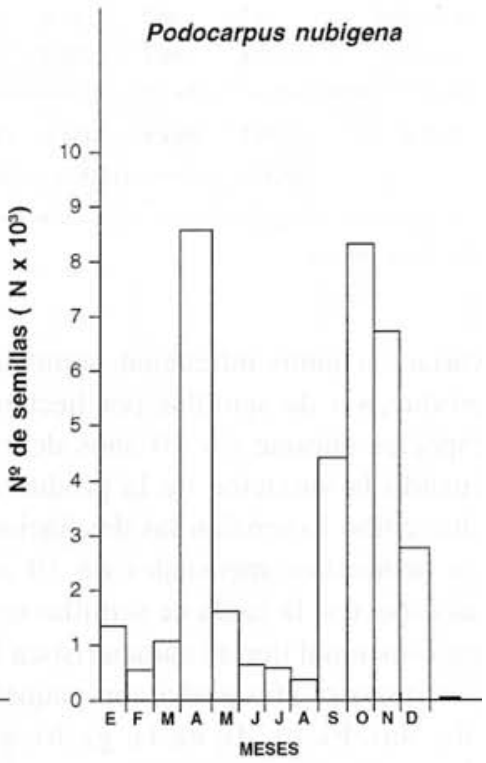

Figura 4. Producción mensual promedio (10 años) de semillas
a) Laurelia philippiana
b) Saxegothaea conspicua
c) Amomyrtus luma
d) Eucryphia cordifolia
e) Aextoxicon punctatum
f) Podocarpus nubigena
g) Amomyrtus meli
h) Gevuina avellana
i) Drimys winteri

obtenida en bosques de la Cordillera de la Costa de Valdivia. El orden de los meses indica la secuencia natural de caída de semillas desde su inicio hasta su declinación máxima.

Monthly average seed production (10 years) of:
a) Laurelia philippiana
b) Saxegothaea conspicua
c) Amomyrtus luma
d) Eucryphia cordifolia
e) Aextoxicon punctatum
f) Podocarpus nubigena
g) Amomyrtus meli
h) Gevuina avellana
i) Drimys winteri

obtained from forests of the Coastal Range of Valdivia. Months are arranged from the initiation to the end of seed fall period. 
Fig. $4 \mathrm{~g}$

Amomyrtus meli

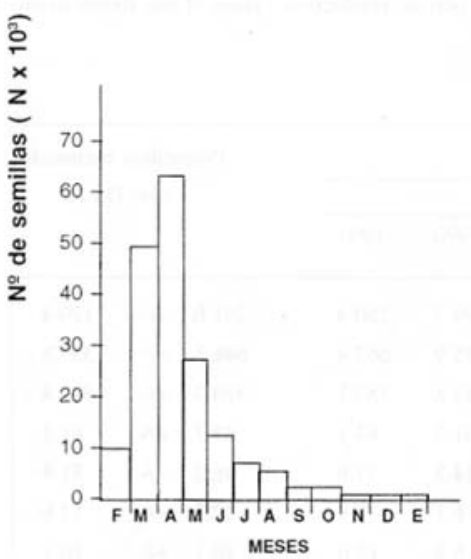

Fig. $4 \mathrm{~h}$

Gevuina avellana

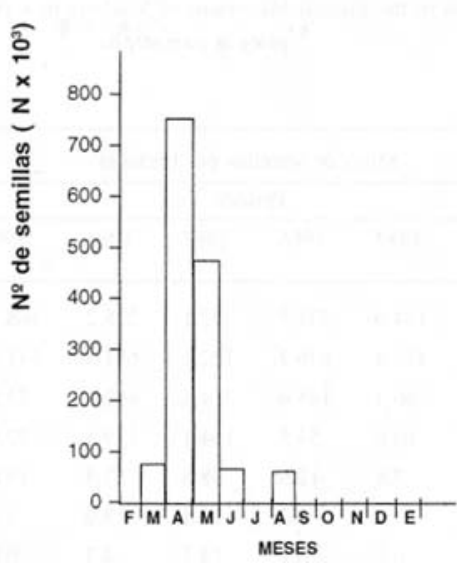

Fig. 4i

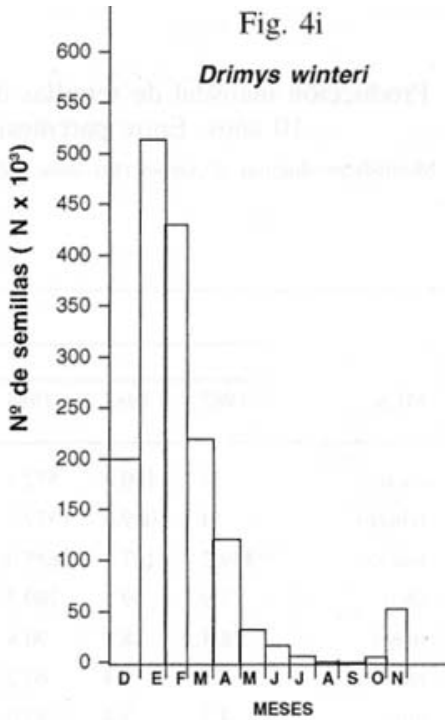

\section{CUADRO 3}

Producción mensual de semillas de Saxegothaea conspicua en la Cordillera de la Costa de Valdivia en el período de 10 años. Entre paréntesis valores de producción de las parcelas bajo método de protección. Monthly production of Saxegothaea conspicua seeds in the Coastal Mountains of Valdivia in a 10 years period. Production values of the shelterwood plots in parenthesis.

\begin{tabular}{|c|c|c|c|c|c|c|c|c|c|c|c|c|c|}
\hline \multirow[b]{3}{*}{ MES } & \multicolumn{10}{|c|}{ Miles de semillas por hectárea } & \multirow{2}{*}{\multicolumn{3}{|c|}{$\begin{array}{c}\text { Promedios mensuales } \\
\text { (+/ D.E.) }\end{array}$}} \\
\hline & \multicolumn{10}{|c|}{ Período } & & & \\
\hline & 1982 & 1983 & 1984 & 1985 & 1986 & 1987 & 1988 & 1989 & 1990 & 1991 & & & \\
\hline enero & SI & 208.3 & 0.0 & 1124.5 & 1695.3 & 0.0 & 4.1 & 288.4 & 1821.1 & 30.6 & 517.2 & $+/-$ & 759.1 \\
\hline febrero & SI & 74.8 & 2.0 & 1537 & 707.5 & 0.0 & 2.0 & 238.2 & 270.7 & 14.5 & 146.3 & $+/-$ & 229.8 \\
\hline marzo & 1.3 & 2.1 & 0.0 & 17.7 & 117.7 & 0.0 & 1.4 & 16.4 & 33.3 & 2.0 & 19.2 & $+/-$ & 36.3 \\
\hline abril & 0.0 & 07 & 1.4 & 16.3 & 41.9 & 0.7 & 3.4 & 6.8 & 34.7 & 0.0 & 10.6 & $+/-$ & 15.5 \\
\hline mayo & 0.7 & 0.0 & 1.4 & 2.0 & 16.3 & 0.0 & 0.0 & 4.1 & 76.2 & 4.1 & 10.5 & $+/-$ & 23.6 \\
\hline junio & 0.7 & 0.0 & 0.0 & 1.4 & 8.8 & 0.8 & 07 & 10.2 & 9.3 & 0.7 & 3.3 & $+/-$ & 4.3 \\
\hline julio & 0.7 & 0.0 & 0.0 & 0.0 & 9.5 & 0.0 & 0.0 & 0.0 & 3.4 & 0.0 & 1.4 & $+/-$ & 3.1 \\
\hline agosto & 0.0 & 0.0 & 3.1 & 0.7 & 7.5 & 0.7 & 0.0 & 1.4 & 4.1 & 1.4 & 1.9 & $+/-$ & 2.4 \\
\hline septiembre & 0.0 & 0.0 & 3.1 & 8.8 & 4.8 & 0.0 & 0.0 & 0.0 & 0.0 & 1.4 & 1.8 & $+/-$ & .3 .0 \\
\hline octubre & 0.0 & 0.0 & 2.0 & 2.7 & 0.0 & 0.0 & 0.0 & 0.0 & 0.0 & 1.4 & 0.6 & $+/-$ & 1.0 \\
\hline noviembre & 0.0 & 0.7 & 0.0 & 0.7 & 1.4 & 0.0 & 0.7 & 0.0 & 0.0 & 0.0 & 0.4 & $+/-$ & 0.5 \\
\hline diciembre & 0.0 & 1.4 & 0.0 & 72,1 & 0.0 & 0.0 & 3.0 & 6.8 & 1.4 & 0.0 & 8.5 & $+/-$ & 22.5 \\
\hline TOTAL & 3.4 & 288.0 & 12.9 & 1400.7 & 2610.7 & 2.2 & 15.3 & 572.3 & 2254.2 & 56.1 & 721.6 & $+/-$ & 1101.1 \\
\hline & & $(2.0)$ & $(4.0)$ & $(80.0)$ & (936.2) & (2.0) & (16.1) & $(170.2)$ & (249.4) & (12.0) & $(250.4)$ & $+/$ & $(378.6)$ \\
\hline
\end{tabular}

$\mathrm{SI}=\mathrm{Sin}$ información

El patrón de caída mensual de semillas durante un período como promedio para Aextoxicon punctatum se aprecia en la fig. 4e. Sin embargo, la caída de semillas se inicia en forma variable entre diciembre de un año y marzo del siguiente (cuadro 6). Del mismo modo la máxima caída se produce en promedio en abril o mayo generalmente, pero no siempre (cuadro 6). La caída de semilla dismi- 
CUADRO 4

Producción mensual de semillas de Amomyrtus luma en la Cordillera de la Costa de Valdivia en el período de 10 años. Entre paréntesis valores de producción de las parcelas bajo método de protección.

Monthly production of Amomyrtus luma seeds in the Coastal Mountains of Valdivia in a 10 years period. Production values of the shelterwood plots in parenthesis.

\begin{tabular}{|c|c|c|c|c|c|c|c|c|c|c|c|c|}
\hline \multirow[b]{3}{*}{ MES } & \multicolumn{10}{|c|}{ Miles de semillas por hectárea } & \multirow{2}{*}{\multicolumn{2}{|c|}{$\begin{array}{c}\text { Promedios mensuales } \\
(+/ \text { D.E. })\end{array}$}} \\
\hline & \multicolumn{10}{|c|}{ Período } & & \\
\hline & 1982 & 1983 & 1984 & 1985 & 1986 & 1987 & 1988 & 1989 & 1990 & 1991 & & \\
\hline enero & SI & 180.3 & 572.3 & 134.0 & 531.3 & 372.1 & 278.2 & 168.5 & 99.3 & 280.4 & 261.6 & 170.4 \\
\hline febrero & SI & 1089.8 & 1379.6 & 475.4 & 836.7 & 722.1 & 691.8 & 141.9 & 475.9 & 667.4 & 648.1 & 359.8 \\
\hline marzo & 459.2 & 167.3 & 1633.0 & 50.3 & 145.6 & 214.3 & 652.6 & 73.5 & 43.6 & 353.1 & 379.3 & 482.4 \\
\hline abril & 27.9 & 59.2 & 289.3 & 10.0 & 53.5 & 104.1 & 139.3 & 27.9 & 61.2 & 84.1 & 85.7 & 81.2 \\
\hline mayo & 18.4 & 8.8 & 90.8 & 7.8 & 12.9 & 58.5 & 57.5 & 15.0 & 14.3 & 77.6 & 36.2 & 31.8 \\
\hline junio & 7.5 & 7.4 & 60.2 & 2.0 & 2.7 & 14.3 & 19.0 & 2.8 & 6.1 & 3.4 & 12.5 & 17.6 \\
\hline julio & 4.7 & 3.4 & 33.0 & 0.7 & 6.1 & 14.3 & 14.7 & 0.0 & 6.8 & 17.0 & 10.1 & 10.1 \\
\hline agosto & 1.3 & 2.0 & 33.5 & 2.0 & 10.2 & 20.4 & 10.2 & 2.1 & 4.1 & 6.1 & 9.2 & 10.4 \\
\hline septiembre & 0.7 & 0.0 & 6.6 & 1.4 & 3.4 & 8.2 & 7.5 & 0.0 & 1.4 & 2.7 & 3.2 & $+/-$ \\
\hline octubre & 0.0 & 1.4 & 4.9 & 0.0 & 2.7 & 7.5 & 2.1 & 0.0 & 0.0 & 3.4 & 2.2 & $+/-$ \\
\hline noviembre & 0.0 & 2.0 & 10.0 & 1.4 & 0.7 & 2.0 & 2.1 & 0.7 & 07 & 0.7 & 2.0 & $+/-$ \\
\hline diciembre & 0.7 & 4.8 & 2.7 & 9.5 & 11.6 & 3.4 & 0.7 & 2.7 & 30.4 & 0.0 & 6.7 & $+/-$ \\
\hline TOTAL & 520.4 & 1526.4 & 4115.9 & 694.5 & 1617.4 & 1541.2 & 1875.7 & 435.1 & 743.8 & 1495.9 & 1456.6 & 1181.2 \\
\hline & & (116.0) & $(4070.0)$ & (1303.2) & (1336.9) & (492.0) & $(382.3)$ & $(50.6)$ & (254.0) & (422.0) & (936.3) & $+/-(1.265 .3)$ \\
\hline
\end{tabular}

$\mathrm{SI}=\operatorname{Sin}$ información

\section{CUADRO 5}

Producción mensual de semillas de Eucryphia cordifolia en la Cordillera de la Costa de Valdivia en el período de 10 años. Entre paréntesis valores de producción de las parcelas bajo método de protección.

Monthly production of Eucryphia cordifolia seeds in the Coastal Mountains of Valdivia in a 10 years period. Production values of the shelterwood plots in parenthesis.

\begin{tabular}{|c|c|c|c|c|c|c|c|c|c|c|c|c|c|}
\hline \multirow[b]{3}{*}{ MES } & \multicolumn{10}{|c|}{ Miles de semillas por hectárea } & \multirow{2}{*}{\multicolumn{3}{|c|}{$\begin{array}{l}\text { Promedios mensuales } \\
\text { (+/- D.E.) }\end{array}$}} \\
\hline & \multicolumn{10}{|c|}{ Período } & & & \\
\hline & $1982-83$ & $1983-84$ & $1984-85$ & $1985-86$ & $1986-87$ & $1987-88$ & $1988-89$ & $1989-90$ & $1990-91$ & $1991-92$ & & & \\
\hline abril & 175.5 & 362.6 & 97.8 & 28.6 & 110.3 & 99.3 & 134.7 & 19.7 & 15.6 & 55.1 & 109.9 & $+/-$ & 106.9 \\
\hline mayo & 306.8 & 494.1 & 296.7 & 507.5 & 168.7 & 2857 & 19.2 & 36.7 & 70.7 & 262.6 & 244.9 & $+/-$ & 173.3 \\
\hline junio & 225.8 & 137.0 & 125.9 & 472.8 & 91.8 & 134.7 & 47.6 & 17.7 & 80.2 & 91.8 & 142.5 & $+/-$ & 12.1 \\
\hline julio & 27.2 & 66.6 & 31.6 & 141.6 & 25.9 & 52.4 & 7.8 & 5.0 & 59.9 & 53.1 & 47.1 & $+/-$ & 39.4 \\
\hline agosto & 24.3 & 9.5 & 47.9 & 32.7 & 8.8 & 27.2 & 12.1 & 14.4 & 17.0 & 8.2 & 20.2 & $+/-$ & 13.1 \\
\hline septiembre & 7.5 & 2.7 & 12.6 & 24.5 & 3.5 & 17.0 & 18.4 & 1.4 & 17.0 & 17.0 & 12.2 & $+/-$ & 7.9 \\
\hline octubre & 10.2 & 4.7 & 21.6 & 9.5 & 4.8 & 15.5 & 0.0 & 0.7 & 9.5 & 6.8 & 8.3 & $+/-$ & 67 \\
\hline noviembre & 4.1 & 4.0 & 11.7 & 10.2 & 2.7 & 4.1 & 0.8 & 0.0 & 07 & 2.0 & 4.0 & $+/-$ & 3.9 \\
\hline diciembre & 0.7 & 0.7 & 1.3 & 2.0 & 4.1 & 10.2 & 11.6 & 6.1 & 0.0 & 0.0 & 3.7 & $+/-$ & 4.3 \\
\hline enero & 1.3 & 0.0 & 26.5 & 2.0 & 0.0 & 4,8 & 1.4 & 0.0 & 0.0 & 1.4 & 3.7 & $+/-$ & 8.1 \\
\hline febrero & 2.0 & 0.0 & 3.4 & 3.4 & 0.0 & 1.4 & 0.0 & 0.0 & 0.0 & 0.0 & 1.0 & $+/-$ & 1.4 \\
\hline marzo & 0.0 & 41.5 & 2.0 & 21.8 & 0.0 & 6,2 & 0.0 & 3.5 & 9.5 & S I & 9.4 & $+/-$ & 13.9 \\
\hline TOTAL & 785.4 & 112.3 .4 & 679.0 & 1256.6 & 420.6 & 658.5 & 253.6 & 105.2 & 280.1 & 498.0 & 607.0 & $+/-$ & 391.0 \\
\hline & & $(62.5)$ & (195.4) & (538.9) & (91.6) & (251.8) & (105.7) & $(47.2)$ & $(72.0)$ & (216.0) & (175.7) & $+/-$ & (154.8) \\
\hline
\end{tabular}


nuye en forma ostensible en los meses siguientes, pero con mucha variabilidad interanual (fig. 4e, cuadro 6).

El patrón de caída anual de semillas a lo largo del año para Podocarpus nubigena puede interpretarse como característico (fig. 4f). No se puede fijar en él un inicio de caída de semillas, seguido de un máximo y una disminución posterior. Se distingue en cambio un máximo en abril, que es muy claro en el promedio, pero que analizando todos los años evaluados, es determinado especialmente por la alta producción de abril de 1983 (cuadro 7). Luego se vuelven a presentar altas producciones en septiembre, octubre, noviembre y diciembre, con los máximos generalmente en octubre o noviembre (cuadro 7, fig. 4f). Ello parece representar dos máximos de producción anual cuya explicación no se ha buscado aún.

Amomyrtus meli puede iniciar la caída de semillas en febrero (fig. $4 \mathrm{~g}$ ), pero ella se produce también en marzo en muchas oportunidades (períodos 85-86, 90-91 y 91-92). El máximo de caída normal se produce en abril (fig. $4 \mathrm{~g}$ ), pero en ocasiones puede ocurrir en marzo (períodos 87-88 y 91-92) o en mayo (período 85-86) (cuadro 8).

Gevuina avellana tiene baja producción en este bosque y ella se concentra en marzo y abril, habiendo rara vez caída de semillas en otros meses (fig. 4h, cuadro 9).

Es claro, observando la fig. 4i y el cuadro 10 , que Drimys winteri inicia la caída de semillas en forma normal en diciembre, aunque ello puede ocurrir algunos años en noviembre, como en los períodos 85-86, 86-87, 88-89 y 90-91 (cuadro 10). El máximo de caída de semillas se produce normalmente en enero (fig. 4i); sin embargo, en algunos períodos suele ocurrir en febrero (1985-86 y 1988-89). A partir de marzo, la caída disminuye gradual pero consistentemente hasta el inicio de la nueva producción en el período siguiente (fig. 4i y cuadro 10).

En bosques intervenidos mediante tratamientos silviculturales en la Cordillera de la Costa de Valdivia

Durante 3 períodos consecutivos en 3 parcelas de tala rasa y durante 4 en 3 parcelas de árbol semillero se muestreó la caída de semillas (cuadro 11).

Las cantidades de semillas por hectárea encontradas en las parcelas de tala rasa y árboles semilleros (cuadro 11) son muy bajas en todos los pe- ríodos muestreados si se comparan con aquellas obtenidas en las parcelas sin intervención (cuadros 2 al 10).

En las parcelas de tratamientos de protección se encuentran mayores cantidades de semillas por especie en los 9 años evaluados si se comparan con los tratamientos de tala rasa y árboles semilleros, lo que era esperable, puesto que quedó en pie en cada parcela 20 a $30 \%$ del total de árboles y 40 a $50 \%$ del área basal, valores que representan a árboles de gran tamaño relativo y, por lo tanto, eventuales productores de semillas (cuadros 2 al 8 y cuadro 10; valores totales entre paréntesis).

a) Viabilidad de las semillas caídas en bosques no intervenidos

La viabilidad mensual promedio de las semillas caídas de las siete especies en rodales no intervenidos se presenta en el cuadro 12.

En Laurelia philippiana los meses de mayor producción son marzo, abril, mayo y junio y los de más alta viabilidad, febrero, marzo, abril, mayo y junio. En los meses que siguen a partir de julio, disminuye la producción y al mismo tiempo la viabilidad (cuadros 2 y 12). La correlación entre monto de producción mensual y viabilidad es $\mathrm{r}=$ 0.74. Del mismo modo, los años evaluados de más alta viabilidad para $L$. philippiana coinciden con los de mayor producción (1987 y 1990) y los de más baja viabilidad con los de menor producción (1988 y 1991).

En Eucryphia cordifolia la producción de semillas y la viabilidad más alta se producen en mayo y abril, respectivamente, y disminuyen gradualmente hasta octubre (cuadros 5 y 12). La correlación entre el monto de producción mensual y la viabilidad es $r=0.81$. También coinciden en esta especie los años de alta producción con la mayor viabilidad (1987 y 1991) y los de más baja producción con los de menor viabilidad (1988 y 1990).

Los meses de más alta producción en Drimys winteri, que ocurre entre diciembre y junio, son también de alta viabilidad, pero no hay una clara correlación ( $\mathrm{r}=0.47$; cuadros 10 y 12). Generalmente, cuando hay producción en un mes, aunque las semillas sean escasas, la viabilidad es regular a alta.

En los cuadros 3, 4, 7, 8 y 12 se aprecia que en las especies $S$. conspicua, A. luma, $P$. nubigena $y$ A. meli se repite la coincidencia entre los meses de alta producción con la alta viabilidad de las semillas, con algunas excepciones de algunos 


\section{CUADRO 6}

Producción mensual de semillas de Aextoxicon punctatum en la Cordillera de la Costa de Valdivia en el período de 10 años. Entre paréntesis valores de producción de las parcelas bajo método de protección.

Monthly production of Aextoxicon punctatum seeds in the Coastal Mountains of Valdivia in a 10 years period. Production values of the shelterwood plots in parenthesis.

\begin{tabular}{|c|c|c|c|c|c|c|c|c|c|c|c|c|c|}
\hline \multirow[b]{3}{*}{ MES } & \multicolumn{10}{|c|}{ Miles de semillas por hectárea } & \multirow{2}{*}{\multicolumn{3}{|c|}{$\begin{array}{c}\text { Promedios mensuales } \\
\text { (+/- D.E.) }\end{array}$}} \\
\hline & \multicolumn{10}{|c|}{ Período } & & & \\
\hline & $1981-82$ & $1982-83$ & 1983-84 & $1984-85$ & $1985-86$ & 1986-87 & $1987-88$ & 1988-89 & $1989-90$ & $1990-91$ & & & \\
\hline diciembre & SI & 4.1 & 0.0 & 0.0 & 0.0 & 0.0 & 0.0 & 0.0 & 11.6 & 2.7 & 1.8 & & 3.9 \\
\hline enero & SI & 6.1 & 0.0 & 8.1 & 0.7 & 0.0 & 0.0 & 0.0 & 10.9 & 2.7 & 2.9 & $+/-$ & 4.2 \\
\hline febrero & SI & 0.7 & 2.0 & 0.7 & 2.7 & 0.0 & 1.4 & 0.0 & 0.7 & 1.4 & 1.0 & $+/-$ & 0.9 \\
\hline marzo & 0.0 & 0.7 & 12.2 & 0.0 & 10.9 & 0.0 & 1.4 & 5.4 & 4.2 & 1.4 & 3.6 & $+/-$ & 4.6 \\
\hline abril & 12.2 & 12.2 & 11.9 & 0.0 & 10.2 & 0.7 & 15.3 & 2.7 & 12.2 & 10.2 & 8.8 & $+/-$ & 5.4 \\
\hline mayo & 23.1 & 5.4 & 13.9 & 6.1 & 7.5 & 0.0 & 45.6 & 5.4 & 0.7 & 4.1 & 11.2 & $+/-$ & 13.9 \\
\hline junio & 0.7 & 4.0 & 0.0 & 0.0 & 1.4 & 0.0 & 8.2 & 07 & 0.0 & 0.7 & 1.6 & $+/-$ & 2.6 \\
\hline julio & 0.0 & 0.0 & 0.0 & 0.0 & 07 & 0.0 & 2.1 & 2.1 & 0.0 & 0.0 & 0.5 & $+/-$ & 0.8 \\
\hline agosto & 0.0 & 0.0 & 0.0 & 0.7 & 0.0 & 0.0 & 4.0 & 0.7 & 0.0 & 0.0 & 0.5 & $+/-$ & 1.3 \\
\hline septiembre & 0.0 & 0.0 & 07 & 0.0 & 0.0 & 0.0 & 4.1 & 2.8 & 0.0 & 0.0 & 0.8 & $+/-$ & 1.5 \\
\hline octubre & 0.0 & 0.0 & 0.0 & 0.0 & 0.7 & 0.0 & 2.8 & 1.4 & 0.0 & 0.0 & 0.5 & $+/-$ & 0.9 \\
\hline noviembre & 0.0 & 1.3 & 4.8 & 0.0 & 0.0 & 0.0 & 0.0 & 0.0 & 0.0 & 0.0 & 0.6 & $+/-$ & 1.5 \\
\hline TOTAL & 36.0 & $\begin{array}{r}34.5 \\
(197)\end{array}$ & $\begin{array}{r}45.5 \\
(68.0)\end{array}$ & $\begin{array}{r}15.6 \\
(14,0)\end{array}$ & $\begin{array}{r}34.8 \\
(366.3)\end{array}$ & $\begin{array}{r}0.7 \\
(2.0)\end{array}$ & $\begin{array}{r}84.9 \\
(52.1)\end{array}$ & $\begin{array}{r}21.2 \\
(26.5)\end{array}$ & $\begin{array}{r}40.3 \\
(16.0)\end{array}$ & $\begin{array}{r}23.2 \\
(56.0)\end{array}$ & $\begin{array}{r}33.7 \\
(68.9)\end{array}$ & $\begin{array}{l}+/- \\
+/-\end{array}$ & $\begin{array}{r}41.5 \\
(113.7)\end{array}$ \\
\hline
\end{tabular}

$\mathrm{SI}=\mathrm{Sin}$ información

\section{CUADRO 7}

Producción mensual de semillas de Podocarpus nubigena en la Cordillera de la Costa de Valdivia en el período de 10 años. Entre paréntesis valores de producción de las parcelas bajo método de protección.

Monthly production of Podocarpus nubigena seeds in the Coastal Mountains of Valdivia in a 10 years period. Production values of the shelterwood plots in parenthesis.

\begin{tabular}{|c|c|c|c|c|c|c|c|c|c|c|c|c|c|}
\hline \multirow[b]{3}{*}{ MES } & \multicolumn{10}{|c|}{ Miles de semillas por hectárea } & \multirow{2}{*}{\multicolumn{3}{|c|}{$\begin{array}{c}\text { Promedios mensuales } \\
\text { (+/- D.E.) }\end{array}$}} \\
\hline & \multicolumn{10}{|c|}{ Período } & & & \\
\hline & 1982 & 1983 & 1984 & 1985 & 1986 & 1987 & 1988 & 1989 & 1990 & 1991 & & & \\
\hline enero & SI & 1.4 & 4.1 & 0.0 & 0.0 & 0.0 & 1.4 & 4.3 & 0.7 & 0.7 & 1.4 & $+/-$ & 1.7 \\
\hline febrero & SI & 0.7 & 0.0 & 0.0 & 0.7 & 0.0 & 0.0 & 2.0 & 0.7 & 0.0 & 0.5 & $+/-$ & 0.7 \\
\hline marzo & 0.0 & 0.0 & 0.0 & 0.0 & 3.4 & 0.0 & 0.0 & 3.4 & 0.7 & 3.4 & 1.1 & $+/-$ & 1.6 \\
\hline abril & 4.1 & 65.3 & 1.0 & 4.1 & 3.4 & 0.7 & 0.0 & 2.7 & 9.4 & 2.7 & 9.3 & $+/-$ & 20.0 \\
\hline mayo & 2.0 & 0.0 & 1.0 & 2.0 & 2.0 & 0.0 & 0.7 & 3.4 & 2.0 & 2.0 & 1.5 & $+/-$ & 1.1 \\
\hline junio & 0.0 & 0.0 & 0.0 & 0.0 & 0.0 & 4.8 & 0.7 & 0.7 & 0.0 & 0.0 & 0.6 & $+/-$ & 1.5 \\
\hline julio & 0.0 & 0.0 & 0.0 & 0.0 & 0.0 & 0.0 & 0.7 & 5.1 & 0.0 & 0.0 & 0.6 & $+/-$ & 1.6 \\
\hline agosto & 1.4 & 0.0 & 0.9 & 0.0 & 0.0 & 0.7 & 0.0 & 0.0 & 0.0 & 0.7 & 0.4 & $+/-$ & 0.5 \\
\hline septiembre & 4.1 & 0.0 & 2.5 & 4.1 & 1.4 & 5.4 & 9.2 & 6.9 & 1.4 & 8.8 & 4.4 & $+/-$ & 3.2 \\
\hline octubre & 2.7 & 0.0 & 1.7 & 9.5 & 7.5 & 17.0 & 20.5 & 1.4 & 7.2 & 31.3 & 9.9 & $+/-$ & 8.5 \\
\hline noviembre & 20.4 & 1.3 & 1.3 & 10.9 & 0.7 & 2.0 & 6.1 & 10.2 & 1.4 & 12.6 & 6.7 & $+/-$ & 6.6 \\
\hline diciembre & 6.8 & 0.0 & 0.7 & 2.0 & 0.7 & 3.4 & 3.6 & 8.2 & 0.7 & 2.0 & 2.8 & $+/-$ & \\
\hline TOT A L & 41.5 & $\begin{array}{l}68.7 \\
(2.0)\end{array}$ & $\begin{array}{r}13.2 \\
(0.0)\end{array}$ & $\begin{array}{r}32.6 \\
(14.0)\end{array}$ & $\begin{array}{r}19.8 \\
(4.0)\end{array}$ & $\begin{array}{r}34.0 \\
(44.0)\end{array}$ & $\begin{array}{r}42.9 \\
(12.7)\end{array}$ & $\begin{array}{r}48.3 \\
(14.0)\end{array}$ & $\begin{array}{l}24.2 \\
(2.0)\end{array}$ & $\begin{array}{r}64.2 \\
(30.0)\end{array}$ & $\begin{array}{r}39.1 \\
(13.6)\end{array}$ & $\begin{array}{l}+/- \\
+/-\end{array}$ & $\begin{array}{r}47.0 \\
(14.7)\end{array}$ \\
\hline
\end{tabular}

$\mathrm{SI}=\mathrm{Sin}$ información 


\section{CUADRO 8}

Producción mensual de semillas de Amomyrtus meli en la Cordillera de la Costa de Valdivia en el período de 10 años. Entre paréntesis valores de producción de las parcelas bajo método de protección.

Monthly production of Amomyrtus meli seeds in the Coastal Mountains of Valdivia in a 10 years period. Production values of the shelterwood plots in parenthesis.

\begin{tabular}{|c|c|c|c|c|c|c|c|c|c|c|c|c|c|}
\hline \multirow[b]{3}{*}{ MES } & \multicolumn{10}{|c|}{ Miles de semillas por hectárea } & \multirow{2}{*}{\multicolumn{3}{|c|}{$\begin{array}{c}\text { Promedios mensuales } \\
\text { (+/- D.E.) }\end{array}$}} \\
\hline & \multicolumn{10}{|c|}{ Período } & & & \\
\hline & $1982-83$ & $1983-84$ & 1984-85 & $1985-86$ & $1986-87$ & $1987-88$ & $1988-89$ & $1989-90$ & $1990-91$ & $1991-92$ & & & \\
\hline febrero & SI & 9.5 & 0.7 & 0.0 & 8.8 & 54.4 & 3.4 & 0.7 & 0.0 & 0.0 & 7.8 & $+/-$ & 17.6 \\
\hline marzo & 30.6 & 51.0 & 16.3 & 21.2 & 15.0 & 205.4 & 137.1 & 4.1 & 3.4 & 12.9 & 49.7 & $+/-$ & 67.5 \\
\hline abril & 87.1 & 57.1 & 49.2 & 29.9 & 4.7 & 193.2 & 184.1 & 5.4 & 2.7 & 7.5 & 62.1 & $+/-$ & 72.2 \\
\hline mayo & 15.0 & 30.4 & 15.0 & 50.3 & 0.0 & 73.5 & 90.3 & 4.8 & 2.0 & 1.4 & 28.3 & $+/-$ & 32.2 \\
\hline junio & 6.1 & 6.8 & 17.4 & 25.2 & 0.7 & 34.7 & 21.8 & 1.4 & 2.0 & 2.0 & 11.8 & $+/-$ & 12.1 \\
\hline julio & 4.1 & 2.7 & 9.2 & 4.8 & 0.0 & 28.6 & 19.8 & 1.4 & 0.7 & 2.7 & 7.4 & $+/-$ & 9.0 \\
\hline agosto & 2.0 & 2.0 & 3.6 & 1.4 & 1.4 & 37.4 & 13.6 & 0.0 & 0.7 & 2.7 & 6.5 & $+/-$ & 11.5 \\
\hline septiembre & 1.4 & 0.7 & 1.8 & 0.0 & 0.7 & 16.3 & 3.4 & 0.0 & 0.0 & 0.7 & 2.5 & $+/-$ & 5.2 \\
\hline octubre & 0.7 & 0.7 & 0.4 & 0.0 & 2.0 & 11.6 & 11.2 & 0.0 & 0.0 & 0.0 & 2.7 & $+/-$ & 4.7 \\
\hline noviembre & 0.7 & 0.0 & 0.2 & 0.7 & 0.0 & 3.4 & 2.0 & 0.7 & 0.0 & 0.0 & 0.8 & $+/-$ & 1.1 \\
\hline diciembre & 0.0 & 1.4 & 0.0 & 0.0 & 0.0 & 2.0 & 2.1 & 0.0 & 0.0 & 0.0 & 0.6 & $+/-$ & 0.9 \\
\hline enero & 0.0 & 0.0 & 0.0 & 0.0 & 0.0 & 2.7 & 0.0 & 0.0 & 0.0 & 0.0 & 0.3 & $+/-$ & 0.9 \\
\hline TOT A L & 147.7 & 162.3 & 113.8 & 133.5 & 33.3 & 663.2 & 488.8 & 18.5 & 11.5 & 29.9 & 180.3 & $+/-$ & 234.9 \\
\hline & & $(200.8)$ & $(864.0)$ & $(832.0)$ & $(134.3)($ & 1072.2) & $(951.8)$ & $(52.0)$ & $(10.0)$ & $(86.0)$ & $(467.0)$ & $+/-$ & $(447.2)$ \\
\hline
\end{tabular}

$\mathrm{SI}=\mathrm{Sin}$ información

\section{CUADRO 9}

Producción mensual de semillas de Gevuina avellana en la Cordillera de la Costa de Valdivia en el período de 10 años.

Monthly production of Gevuina avellana seeds in the Coastal Mountains of Valdivia in a 10 years period.

\begin{tabular}{|c|c|c|c|c|c|c|c|c|c|c|c|c|c|}
\hline \multirow[b]{3}{*}{ MES } & \multicolumn{10}{|c|}{ Miles de semillas por hectárea } & \multirow{2}{*}{\multicolumn{3}{|c|}{$\begin{array}{c}\text { Promedios mensuales } \\
(+/- \text { D.E. })\end{array}$}} \\
\hline & \multicolumn{10}{|c|}{ Período } & & & \\
\hline & $1982-83$ & $1983-84$ & $1984-85$ & $1985-86$ & $1986-87$ & $1987-88$ & $1988-89$ & $1989-90$ & $1990-91$ & $1991-92$ & & & \\
\hline enero & SI & 0.0 & 0.0 & 0.0 & 0.0 & 0.0 & 0.0 & 0.0 & 0.0 & 0.0 & 0.0 & & \\
\hline febrero & SI & 0.0 & 0.0 & 0.0 & 0.7 & 0.0 & 0.0 & 0.0 & 0.0 & 0.0 & 0.1 & $+1-$ & 0.2 \\
\hline marzo & 0.7 & 2.7 & 2.0 & 0.0 & 0.7 & 0.0 & 0.7 & 0.0 & 0.7 & 0.0 & 0.8 & $+1-$ & 0.9 \\
\hline abril & 1.3 & 1.3 & 0.0 & 0.0 & 0.0 & 0.0 & 0.7 & 0.0 & 0.7 & 0.7 & 0.5 & $+/-$ & 0.6 \\
\hline mayo & 0.0 & 0.0 & 0.0 & 0.0 & 0.0 & 0.0 & 0.0 & 0.7 & 0.0 & 0.0 & 0.1 & $+/-$ & 0.2 \\
\hline junio & 0.0 & 0.0 & 0.0 & 0.0 & 0.0 & 0.0 & 0.0 & 0.0 & 0.0 & 0.0 & 0.0 & & \\
\hline julio & 0.0 & 0.0 & 0.0 & 0.7 & 0.0 & 0.0 & 0.0 & 0.0 & 0.0 & 0.0 & 0.1 & $+/-$ & 0.2 \\
\hline agosto & 0.0 & 0.0 & 0.0 & 0.0 & 0.0 & 0.0 & 0.0 & 0.0 & 0.0 & 0.0 & 0.0 & & \\
\hline septiembre & 0.0 & 0.0 & 0.0 & 0.0 & 0.0 & 0.0 & 0.0 & 0.0 & 0.0 & 0.0 & 0.0 & & \\
\hline octubre & 0.0 & 0.0 & 0.0 & 0.0 & 0.0 & 0.0 & 0.0 & 0.0 & 0.0 & 0.0 & 0.0 & & \\
\hline noviembre & 0.0 & 0.0 & 0.0 & 0.0 & 0.0 & 0.0 & 0.0 & 0.0 & 0.0 & 0.0 & 0.0 & & \\
\hline diciembre & 0.0 & 0.0 & 0.0 & 0.0 & 0.0 & 0.0 & 0.0 & 0.0 & 0.0 & 0.0 & 0.0 & & \\
\hline TOT AL & 2.0 & 4.0 & 2.0 & 0.7 & 1.4 & 0.0 & 1.4 & 0.7 & 1.4 & 0.7 & 1.4 & $+/-$ & 2.1 \\
\hline
\end{tabular}


CUADRO 10

Producción mensual de semillas de Drimys winteri en la Cordillera de la Costa de Valdivia en el período de 10 años. Entre paréntesis, valores de producción de las parelas bajo el método de protección

Monthly production of Drimys winteri seeds in the Coastal Mountains of Valdivia in a 10 years period. Production values of the shelterwood plots in parenthesis

\begin{tabular}{|c|c|c|c|c|c|c|c|c|c|c|c|c|c|}
\hline \multirow[b]{3}{*}{ MES } & \multicolumn{10}{|c|}{ Miles de semillas por hectárea } & \multirow{2}{*}{\multicolumn{3}{|c|}{$\begin{array}{l}\text { Promedios mensuales } \\
\text { (+/- D.E.) }\end{array}$}} \\
\hline & \multicolumn{10}{|c|}{ Período } & & & \\
\hline & $1981-82$ & $1982-83$ & 1983-84 & $1984-85$ & $1985-86$ & $1986-87$ & $1987-88$ & 1988-89 & $1989-90$ & $1990-91$ & & & \\
\hline diciembre & SI & 24.5 & 42.8 & 97.3 & 1021.8 & 457.8 & 1.4 & 21.3 & 18.8 & 106.1 & 179.2 & $+/-$ & 339.3 \\
\hline enero & SI & 402.0 & 17.0 & 1401.4 & 919.0 & 509.5 & 0.7 & 413.5 & 821.1 & 147.6 & 463.2 & $+/-$ & 452.8 \\
\hline febrero & SI & 156.5 & 2.0 & 55.7 & 1811.6 & 225.2 & 3.0 & 742.3 & 755.8 & 143.5 & 389.6 & $+/-$ & 393.4 \\
\hline marzo & 272.8 & 15.6 & 0.0 & 32.0 & 1080.3 & 84.6 & 3.4 & 11.9 & 622.8 & 17.9 & 214.1 & $+/-$ & 315.2 \\
\hline abril & 36.1 & 8.8 & 0.0 & 4.8 & 309.1 & 497 & 0.0 & 33.3 & 780.3 & 6.8 & 122.9 & $+/-$ & 249.1 \\
\hline mayo & 18.4 & 0.0 & 0.0 & 5.4 & 93.2 & 29.9 & 0.0 & 13.6 & 219.7 & 6.1 & 38.6 & $+/-$ & 59.5 \\
\hline junio & 8.2 & 0.7 & 0.0 & 0.7 & 83.7 & 6.1 & 0.0 & 6.1 & 108.2 & 2.0 & 21.6 & $+/-$ & 39.7 \\
\hline julio & 4.7 & 07 & 0.0 & 0.0 & 10.2 & 4.8 & 0.0 & 0.7 & 19.4 & 0.0 & 4.1 & $+/$ & 21.1 \\
\hline agosto & 2.0 & 0.0 & 0.0 & 0.0 & 7.5 & 12.9 & 0.0 & 0.7 & 10.2 & 9.5 & 4.3 & $+/-$ & 5.1 \\
\hline septiembre & 1.3 & 0.0 & 0.0 & 0.0 & 13.7 & 5.4 & 0.0 & 0.0 & 4.1 & 0.0 & 2.5 & $+/-$ & 4.4 \\
\hline octubre & 0.0 & 0.0 & 0.0 & 25.8 & 7.5 & 2.0 & 0.0 & 1.4 & 2.0 & 2.7 & 4.1 & $+/-$ & 7.8 \\
\hline noviembre & 0.0 & 0.0 & 0.0 & 355.1 & 159.9 & 0.7 & 8.8 & 0.0 & 47.6 & 3.4 & 57.6 & $+/-$ & 11.9 \\
\hline TOTAL & 343.5 & $\begin{array}{r}608.8 \\
(5.4)\end{array}$ & $\begin{array}{r}61.8 \\
(16.0)\end{array}$ & $\begin{array}{r}1978.2 \\
(1280.0)\end{array}$ & $\begin{array}{r}5517.5 \\
(1042.7)\end{array}$ & $\begin{array}{r}1388.6 \\
(81.9)\end{array}$ & $\begin{array}{r}17.3 \\
(14.1)\end{array}$ & $\begin{array}{c}1244.8 \\
(110.0)\end{array}$ & $\begin{array}{l}3410.0 \\
(222.0)\end{array}$ & $\begin{array}{r}445.6 \\
(2.0)\end{array}$ & $\begin{array}{r}1501.6 \\
(308.2)\end{array}$ & $\begin{array}{l}+/- \\
+/-\end{array}$ & $\begin{array}{r}1919.3 \\
(492.3)\end{array}$ \\
\hline
\end{tabular}

$\mathrm{SI}=\operatorname{Sin}$ información

\section{CUADRO 11}

Recolección mensual de semillas en parcelas de 1 ha intervenidas mediante tala rasa y árboles semilleros. Monthly seed crops in 1 ha plots with clear-cutting and seed tree silvicultural treatments and surrounded by evergreen forests.

\begin{tabular}{|c|c|c|c|c|c|c|c|}
\hline \multirow{3}{*}{ Mes } & \multicolumn{7}{|c|}{ Semillas por hectárea } \\
\hline & \multicolumn{3}{|c|}{ Tala rasa } & \multicolumn{4}{|c|}{ Arboles semilleros } \\
\hline & $1983-84$ & $1984-85$ & $1985-86$ & $1983-84$ & $1984-85$ & $1985-86$ & $1986-87$ \\
\hline L. philippiana & 57.999 & 8.333 & 308.150 & 204.150 & 109.866 & 252.666 & 187.939 \\
\hline E. cordifolia & 25.000 & 28.333 & 76.683 & 7.667 & 62.500 & 372.083 & 97.726 \\
\hline A. punctatum & 25.004 & 5.000 & 85.714 & 63.066 & 90.966 & 39.750 & 35.287 \\
\hline A. meli & 28.327 & 15.000 & 0 & 72.714 & 156.933 & 12.333 & 2.667 \\
\hline A. luma & 14.333 & 34.166 & 96.683 & 494.849 & 702.650 & 269.000 & 73.338 \\
\hline D. diacantoides & 1.660 & 0 & 0 & 2.777 & 1.400 & 0 & 0 \\
\hline S. conspicua & 0 & 1.667 & 0 & 0 & 4.167 & 2.083 & 0 \\
\hline M. ovata & 0 & 6.667 & 0 & 0 & 94.467 & 0 & 0 \\
\hline D. winteri & 0 & 0 & 24.000 & 0 & 99.317 & 46.667 & 31.676 \\
\hline P. nubigena & 0 & 0 & 0 & 0 & 3.500 & 4.000 & 0 \\
\hline$P$. lingue & 0 & 0 & 0 & 0 & 0 & 1.333 & 0 \\
\hline Total & 152.323 & 99.166 & 591.230 & 851.223 & 1.325 .766 & 999.915 & 428.653 \\
\hline
\end{tabular}




\section{CUADRO 12}

Viabilidad mensual promedio de las semillas caídas de distinas especies entre 1986 y 1991 en bosque no intervenido (porcentaje).

Monthly viability percentage of seeds of different species fallen between 1986 and 1991 in natural forest (percentage).

\begin{tabular}{|c|c|c|c|c|c|c|c|c|}
\hline \multirow{2}{*}{ Mes } & \multicolumn{7}{|c|}{ Viabilidad promedio \pm desviación estándar } & \multirow[b]{2}{*}{ D. winteri } \\
\hline & L. philippiana & $E$. & cordifolia & 5. conspicua & P. nubigena & A. luma & A. meli & \\
\hline Enero & $2.78 \pm 4.43$ & & - & $89.7 \pm 9.08$ & - & $94.84 \pm 1.23$ & & $84.63 \pm 7.08$ \\
\hline Febrero & $20.93 \pm 16.5 .3$ & & - & $71.73 \pm 12.98$ & - & $94.78 \pm 2.15$ & $83.00(1)$ & $92.3 .3 \pm 8.04$ \\
\hline Marzo & $18.06 \pm 19.35$ & & - & $35.55 \pm 24.34$ & $100.0(\mathrm{I})$ & $88.42 \pm 6.9$ & $82.05 \pm 15.5$ & $72.6 \pm 19.36$ \\
\hline Abril & $38.85 \pm 36.95$ & 83.80 & \pm 10.54 & $60.13 \pm 17.78$ & $20.0 \pm 00.00$ & $86.4 \pm 9.97$ & $93.47 \pm 6.73$ & $84.62 \pm 6.75$ \\
\hline Mayo & $16.78 \pm 16.68$ & 63.68 & \pm 8.07 & $61.35 \pm 21.99$ & 0 & $77.65 \pm 15.03$ & $43.61 \pm 3.46$ & $80.8 \pm 15.24$ \\
\hline Junio & $12.97 \pm 10.20$ & 62.73 & \pm 14.98 & - & - & - & $78.4(1)$ & $93.8 \pm 3.96$ \\
\hline Julio & $7.88 \pm 8.21$ & 51.23 & \pm 30.1 & - & - & $97.65 \pm 3.39$ & 85.4 (1) & - \\
\hline Agosto & $10.01 \pm 18.20$ & 28.67 & \pm 19.5 & - & - & 59.4 & $21.5 \quad$ (1) & 88.9 (1) \\
\hline Septiembre & $3.22 \pm 3.66$ & 2.3 .6 & \pm 15.69 & & 15.4 (1) & - & 84.0 & $0(1)$ \\
\hline Octubre & $1.5 .3 \pm 1.76$ & 22.1 & \pm 14.8 & - & $79.15 \pm 1.2$ & - & - & 35.5 (1) \\
\hline Noviembre & $0.9 .3 \pm 1.62$ & & - & - & 84.6 (1) & - & - & 42.0 \\
\hline Diciembre & $0.78 \pm 1.19$ & & - & - & & - & - & $86.6 \pm 11.95$ \\
\hline
\end{tabular}

(1) Un solo mes con caída de semillas

(2) Dos meses con caída de semillas

meses en cada especie. Ello queda representado por coeficientes de correlación relativamente bajos, de 0.69 para $S$. conspicua, 0.57 para A. luma, 0.49 para $P$. nubigena y 0.57 para $A$. meli.

b) De las semillas caídas en bosques intervenidos mediante el método de protección uniforme

La viabilidad mensual promedio de las semillas de ciertas especies caídas en rodal siempreverde intervenido por el método de protección uniforme, se muestra en el cuadro 13.

Las tendencias son similares a las observadas en el cuadro 12 para los bosques no intervenidos.

PRODUCCION DE HOJARASCA

La producción de hojarasca más semillas, en términos de peso seco, varía mensualmente entre 0.1727 ton/ha en octubre y 0.4569 ton/ha en enero, valores que representan el promedio de 10 años (fig. 5). A lo largo del período de 10 años hay cierta fluctuación, produciéndose los valores más bajos de peso seco alternativamente en los meses de septiembre (3), octubre (5) y noviembre (2), y los más altos en enero (4), febrero (2) y marzo (4). La tendencia es clara y la longitud del período permite asegurar que la evaluación es suficientemente precisa (Newbold, 1970).
La mayor producción de hojarasca en el bosque siempreverde se distribuye en los meses de verano (diciembre, enero y febrero) y otoño (marzo, abril y mayo), y declina ostensiblemente en los meses de invierno y primavera (cuadro 14). La declinación de la producción en los meses de invierno y primavera es más notoria en las semillas que en la hojarasca, lo que está determinado por la estacionalidad de la producción de semillas y por una probable caída de hojarasca a lo largo de todo el año, sin marcada estacionalidad, debido a la condición de perennifolias de todas las especies. Del mismo modo, la producción de hojarasca en cada estación muestra poca variación en los 10 años evaluados, mientras que la producción de semillas, en términos conceptuales, muestra mayor variación (cuadro 14), lo que es determinado por la fluctuación anual o periodicidad en la producción de las diferentes especies. Sin embargo, el peso seco de las semillas es muy bajo, de tal modo que sus fluctuaciones tienen escasa incidencia en la producción total de hojarasca (valor total absoluto ton/ha/año).

Los valores totales de materia seca producidos por bosques siempreverdes primarios, sin intervención, en la ladera occidental de la Cordillera de la Costa de Valdivia, fluctúan entre 3.10 y 4.54 ton/ ha/año en un período de 10 años de medición, con 


\section{CUADRO 13}

Viabilidad mensual promedio de las semillas caídas de distintas especies entre 1986 y 1991 en bosque bajo tratamiento de protección uniforme $(\%)$.

Monthly viability percentage of seeds of different species fallen between 1986 and 1991 in forests under shelterwood treatment (\%).

\begin{tabular}{|c|c|c|c|c|c|c|c|}
\hline \multirow{2}{*}{ Meses } & \multicolumn{7}{|c|}{ Viabilidad promedio \pm desviación estándar } \\
\hline & L. plrilippiana & E. cordifolia & S. conspicua & P. nubigena & A. luma & A. meli & D. winteri \\
\hline Enero & $3.60 \pm 4.1$ & - & $63.7 \pm 17.5(2)$ & - & $92.6 \pm 2.2$ & $\cdot$ & $96.6 \pm 0.2$ \\
\hline Febrero & $8.4 \pm 5.4$ & - & $67.6 \pm 24.8$ & - & $96.1 \pm 2.8$ & $85.2 \quad$ (1) & $88.5 \pm 3.0$ \\
\hline Marzo & $19.4 \pm 29$ & - & 72.7 (1) & - & $81.7 \pm 12.2$ & $85.5 \pm 14.8(2)$ & - \\
\hline Abril & $38.8 \pm 29.6$ & $87.5 \pm 12.1$ & $\cdot$ & - & 77.7 (1) & $85.1 \pm 7.2$ & 83.3 (1) \\
\hline Mayo & $20.2 \pm 16.2$ & $46.4 \pm 33.4$ & - & $\cdot$ & - & $100.00(1)$ & 86.4 (1) \\
\hline Junio & $9.0 \pm 9.2$ & $34.7 \pm 4.0(2)$ & - & $\cdot$ & - & $78.6(1)$ & $71.4(1)$ \\
\hline Jutio & $6.2 \pm 10.6$ & - & . & - & - & - & 68.8 (1) \\
\hline Agosto & $4.4 \pm 2.9$ & $18.2 \pm 21.4$ & . & - & - & - & - \\
\hline Septiembre & $4.3 \pm 3.2$ & 3.7 (1) & - & - & - & - & - \\
\hline Octubre & $2.3 \pm 3.2(2)$ & 5.5 (1) & - & - & - & - & $\cdot$ \\
\hline Noviembre & $0.0(2)$ & - & - & - & - & - & - \\
\hline Diciembre & $0.0(1)$ & - & - & - & - & - & $77.8 \pm 3(2)$ \\
\hline
\end{tabular}

(1) Un solo mes con caída de semillas

(2) Dos meses con caída de semillas

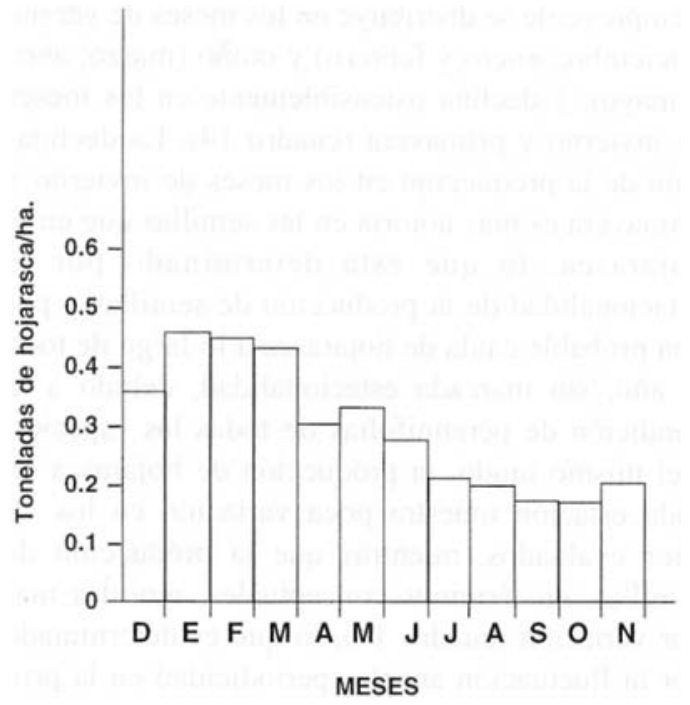

Figura 5. Distribución mensual de la hojarasca caída en el tipo forestal siempreverde costero, de acuerdo al promedio de diez años de registro. Producción total anual: $3,61 \mathrm{t} / \mathrm{ha}$.

Monthly distribution of litterfall in the evergreen forest of the Coastal Range. based on a ten year record. Annual production: 3,61 t/ha.

un valor promedio de 3,61 ton/ha/año (cuadro 14). En los bosques intervenidos por el método silvicultura! de protección uniforme los valores de pro- ducción de materia seca disminuyen claramente respecto de los bosques primarios durante los 9 años de evaluación, alcanzando un promedio de 2.43 y un rango entre 1.81 y 3.49 ton/ha/año (cuadro 14).

VARIACION INTERANUAL Y PERIODICIDAD

L. philippiana, D. winteri, A. luma, S. conspicua, E. cordifolia y A. meli son las especies de mayor incidencia en la producción total del bosque en estudio, en términos de cantidad de semillas por hectárea, representando más del $99 \%$ del total. Además de estas especies se analizan en cuanto o periodicidad A. punctatum y $P$. nubigena.

En 10 años de observaciones no se perfilan ciclos definidos de producción de semillas o variaciones interanuales que muestren ritmos constantes. La excepción en este período la constituye $A$. punctatum, que muestra una tendencia bastante clara a un ritmo bianual, en que se alterna un año de producción alta, generalmente por encima del promedio, y otro de baja producción (fig. 6a).

En $D$. winteri (fig. 6b) y $S$. conspicua (fig. 6c) se puede captar alguna tendencia a un ciclo de un año de alta producción cada tres o cuatro años de producciones bajas a relativamente bajas o inter- 
PRODUCCION DE SEMILLAS Y HOJARASCA EN EL TIPO FORESTAL SIEMPREVERDE

Fig. 6a

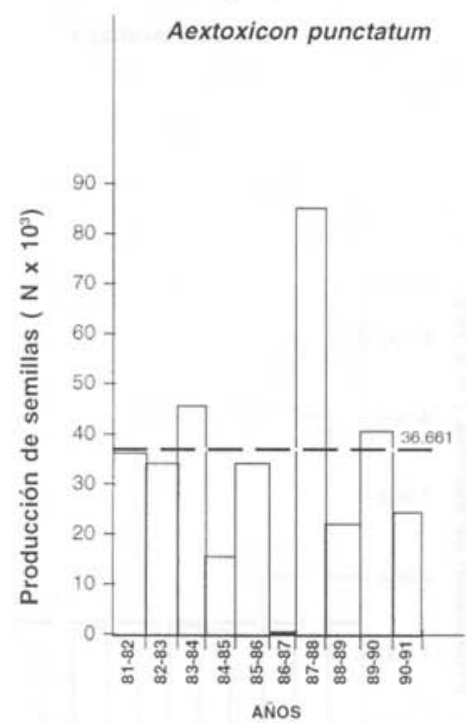

Fig. 6d

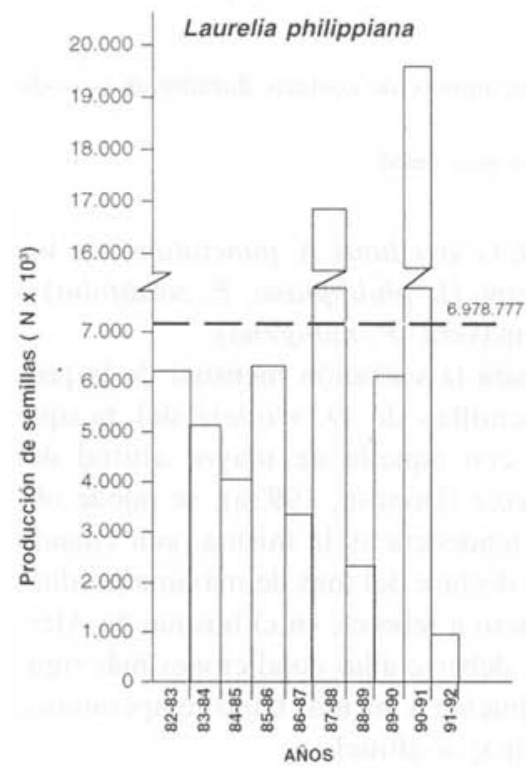

Fig. 6b

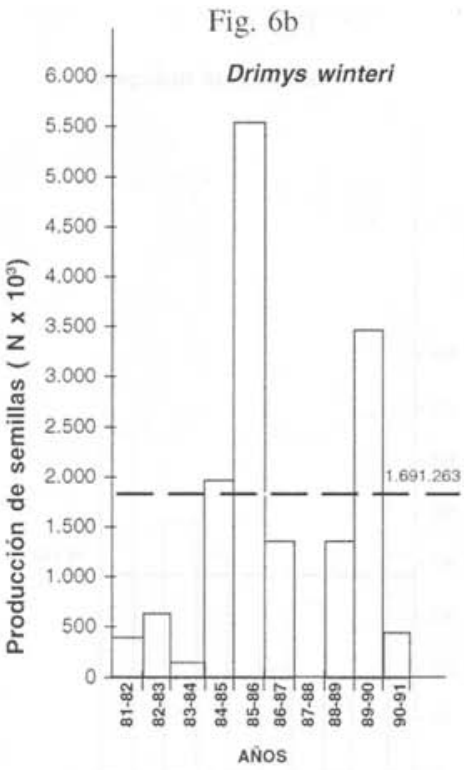

Fig. 6e

Amomyrtus luma

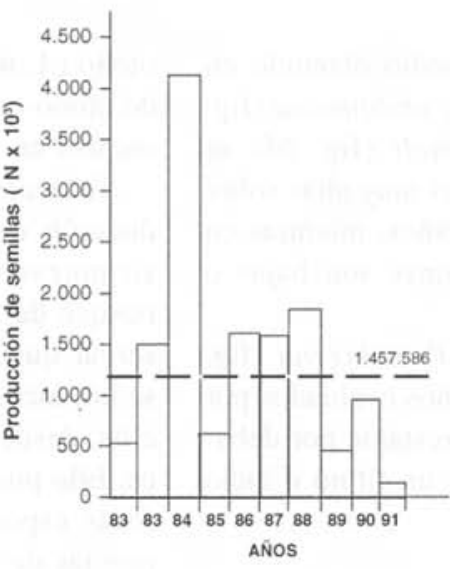

Fig. 6c

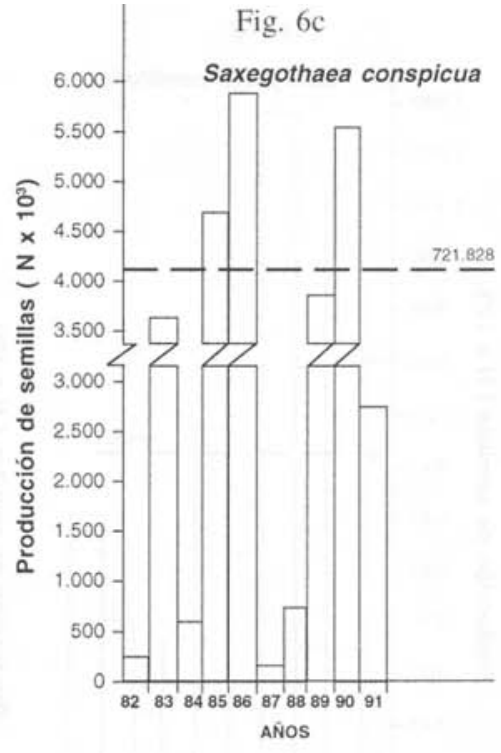

Fig. 6f

Amomyrtus meli

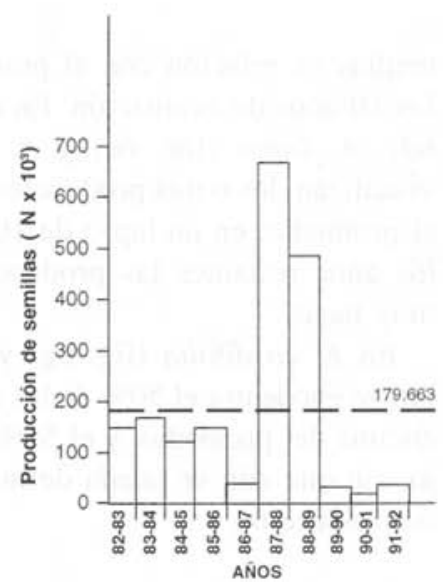


Fig. $6 \mathrm{~g}$

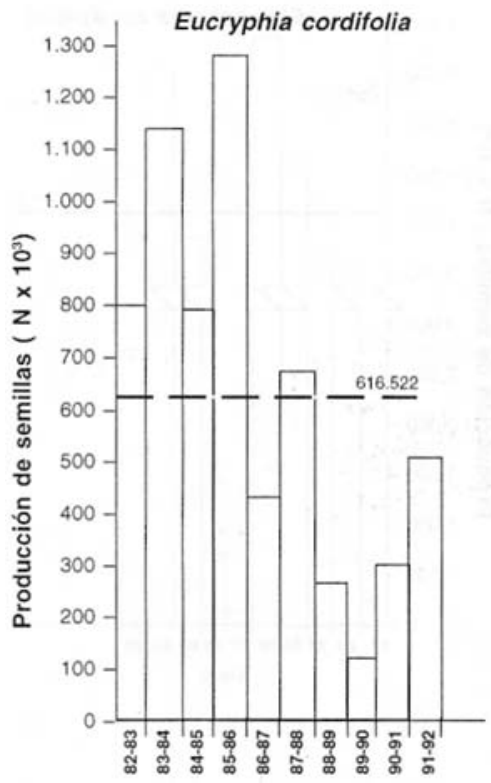

Fig. 6h

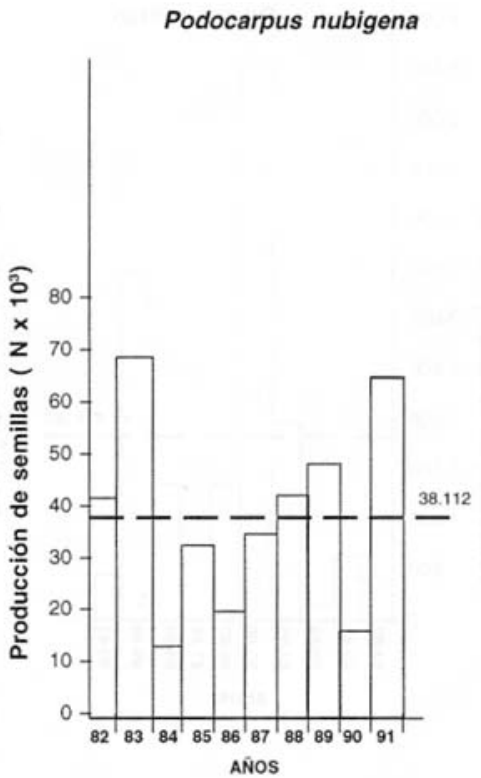

Fig. 6i

Gevuina avellana

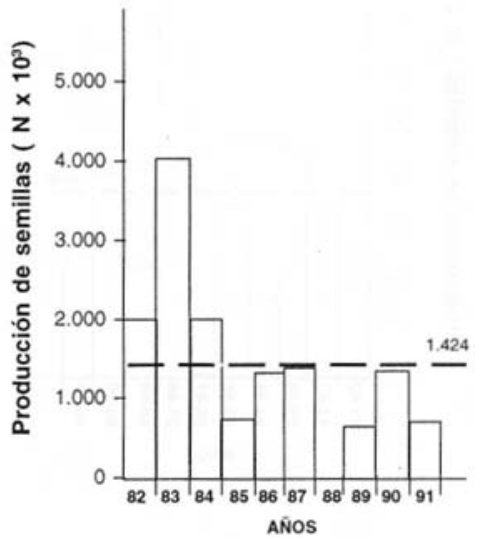

Figura 6. Producción anual de semillas de nueve especies del tipo forestal siempreverde costero, durante un período de diez años.

Annual seed production of nine species of the evergreen forest of the Coastal Range, over a ten years period.

medias en relación con el promedio obtenido en los 10 años de evaluación. En L. philippiana (fig. 6d), A. luma (fig. 6e) y A. meli (fig. 6f) se visualizan dos o tres producciones muy altas sobre el promedio, en un lapso de 10 años, mientras en los años restantes las producciones son bajas o muy bajas.

En $E$. cordifolia (fig. 6g) y $P$. nubigena (fig. 6h) se encuentra el $50 \%$ de los años evaluados por encima del promedio, y el $50 \%$ restante por debajo, sin que aún se pueda definir un ritmo o ciclo de producción.

\section{DISCUSION Y CONCLUSIONES}

Producción de semillas. La gran variación existente entre las especies en cuanto a los meses de más alta producción de semillas refleja que se trata de características específicas, ontogénicas, que no están relacionadas con los factores principales del clima, puesto que éste es el mismo para todas ellas, y nos encontramos con especies que tienen los máximos de producción en los meses de verano (D. winteri, S. conspicua, A. luma), en los de otoño (A. meli, G. avellana, A. punctatum), en los de otoño-invierno (L. philippiana, E. cordifolia) o incluso en primavera ( $P$. nubigena).

$\mathrm{Si}$ se compara la variación mensual de la producción de semillas de $D$. winteri del bosque siempreverde con aquella de mayor altitud del bosque de Alerce (Donoso, 1993a), se puede observar que la tendencia es la misma, aun cuando se produce un desfase del mes de máxima producción, desde enero a febrero, en el bosque de Alerce. Ello puede deberse a las condiciones más rigurosas, especialmente a las más bajas temperaturas, propias de la mayor altitud.

La producción de semillas de A. punctatum en estos bosques fluctúa entre 680 y 84.838 en los diferentes años evaluados, cifra muy inferior a la encontrada por Murúa y González (1985) en un bosque multiespecífico de tierras bajas en Valdivia, en que $A$. punctatum es una especie dominante. En este bosque el rango fluctúa entre 53.484 y 606.547 semillas/ha en los cuatro años evaluados. Algo similar debería ocurrir si se comparan los valores obtenidos en el bosque siempreverde a 600 $\mathrm{m}$ de altitud con los de los bosques de menor altitud y en especial los del subtipo Olivillo costero, don- 
CUADRO 14

Valores porcentuales de producción de semillas y hojarasca por estación del año en 10 períodos anuales consecutivos en el tipo forestal Siempreverde de la Cordillera de la Costa $(\mathrm{S}=$ semillas, $\mathrm{H}=$ hojarasca $)$.

Percentage values of litter production per season during 10 annual periods in the evergreen forest type in the Coastal Mountains $(\mathrm{S}=$ seeds. $\mathrm{H}=\mathrm{litter}$ without seeds $)$

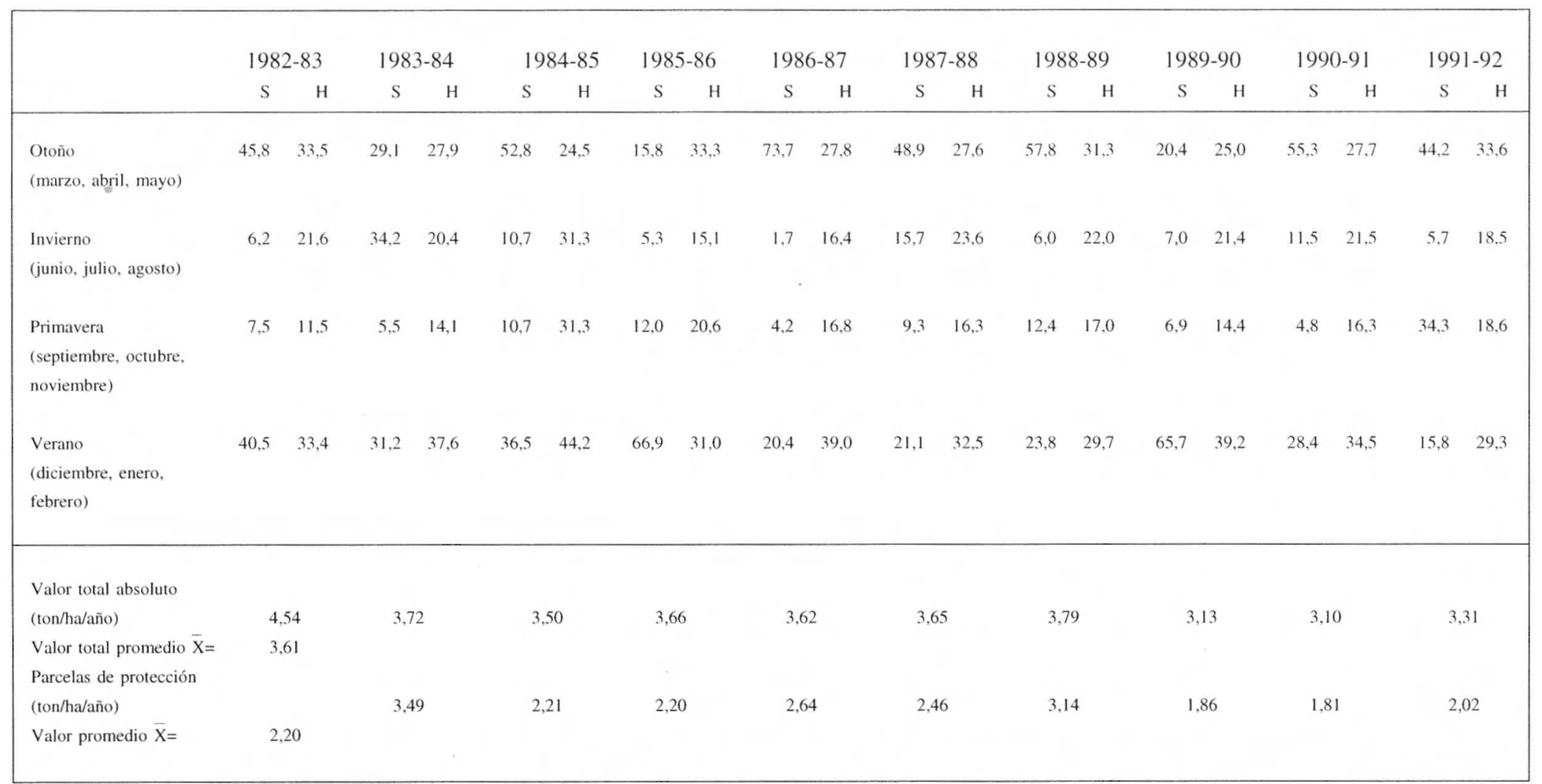


de la especie es totalmente dominante (Donoso, 1981). Hacia mayores altitudes disminuye su frecuencia y a los $600 \mathrm{~m}$ es prácticamente marginal (Donoso, 1989).

$\mathrm{Si}$ se analizan las producciones anuales de semillas de $D$. winteri en el bosque siempreverde y en el bosque de Alerce (Donoso, 1993a), se aprecia también una tendencia a más baja producción en los bosques de mayor altitud en que $D$. winteri se asocia con Fitzroya cupressoides. Sin embargo, por lo menos en un período de alta producción en el bosque de Alerce (1982-83), D. winteri logra 3.982 .900 semillas, mientras que en el siempreverde alcanza sólo 608.757 semillas por hectárea en el mismo período. Este hecho demuestra que las altas o bajas producciones no son necesariamente simultáneas en poblaciones diferentes de la misma especie, incluso cuando son muy próximas, como en este caso.

Las especies que presentan mayor cantidad de árboles por hectárea, L. philippiana, S. conspicua y A. luma, son, junto a $D$. Winteri y E. cordifolia, las que tienen más alta producción en términos de cantidad de semillas por hectárea. De estas especies se esperaba que las anemocoras L. philippiana y E. cordifolia fueran las aportadoras de semillas a los cajones recolectores ubicados en las parcelas de tala rasa y árboles semilleros (en estos últimos los árboles dejados como semilleros fueron $L$. philippiana, E. cordifolia y Weinmannia trichosperma). De las dos primeras se encontraron cantidades relativamente abundantes de semillas, mucho menores que aquellas encontradas en las parcelas no intervenidas, como podía esperarse (cuadro 10 ). Sin embargo, se encontraron cantidades relativamente abundantes de frutos o semillas de A. punctatum, A. meli, y A. luma, y en algunos años de 5. conspicua, $M$. ovata var. ovata, $D$. winteri, y $P$. nubigena, semillas y frutos que son pesados y que en ningún caso pueden haber sido diseminados por el viento hasta los cajones. E1 supuesto es que fueron depositados allí por aves que se pararon en los bordes de los cajones. También se encontraron, en el período 1985-86, en parcelas de árboles semilleros, algunos frutos de Persea lingue, especie muy rara en el área, que pueden haber sido transportados por aves.

Entre los objetivos del método silvicultural de protección está el abrir el dosel para aumentar el espacio de copas y permitir así el desarrollo de éstas en los árboles que quedan en pie, y el consiguiente aumento en la producción de semillas. Si se revisa la información de los cuadros 2 al 9, en lo que se refiere a valores totales de producción de semillas de las parcelas sin intervención y de las parcelas de protección (valores entre paréntesis), puede verse que sólo en tres especies se detecta un aumento de la producción como probable efecto del tratamiento. En L. philippiana se observa una duplicación de la producción en el tercer período después de aplicado el tratamiento, una casi triplicación en el cuarto y en el sexto períodos y aumentos menos importantes en los períodos séptimo y noveno (cuadro 2). En A. meli se aprecia un efecto consistente del tratamiento sobre la producción de semillas especialmente desde el cuarto período hacia adelante, incluyendo el período 9293, que no aparece en el cuadro 8. Finalmente, se observa también un efecto positivo en A. punctatum (cuadro 6).

Estos resultados estarían demostrando que el método silvicultural es apropiado para $L$. philippiana y para A. punctatum, especies de valor maderero conocido, siempre que la calidad de la semilla producida sea buena, de tal modo que pueda germinar y establecerse en el terreno.

La información entregada sobre viabilidad de las semillas caídas corrobora la correlación positiva entre las buenas producciones y la alta viabilidad (Baker, 1950; Daniel, et al., 1982; Donoso, 1993b).

En las especies analizadas la viabilidad es alta en los meses de mayor caída de semillas. Sólo en L. philippiana se encuentra una relativamente baja viabilidad, incluso en los meses de mayor producción, lo que desde el punto de vista de capacidad de regeneración y supervivencia de la especie en el bosque no es relevante, porque la semilla es muy liviana y, por lo tanto, la especie cuenta con una gran cantidad de semillas por kilo (Donoso y Cabello, 1982), lo que significa que 15 y $40 \%$ de viabilidad pueden significar 200.000 a 328.000 semillas germinadas.

Por otro lado, la especie $D$. winteri tiene normalmente alta viabilidad y sin embargo los ensayos de germinación muestran frecuentemente baja capacidad germinativa (Fernández, 1985). Ello se debe a que la semilla posee un embrión inmaduro (Botti y Cabello, 1984), lo que impide la germinación. Sin embargo, una vez en el suelo el embrión madura y cuando se abre el bosque, por un fenómeno alogénico, las semillas logran germinar y establecer abundante regeneración. 
Producción de hojarasca. La mayor concentración de caída de hojarasca en el tipo forestal siempreverde en estudio se produce en los meses de enero, febrero y marzo, es decir, principalmente en verano. En el bosque de Alerce de la misma área, pero a mayor altitud, la máxima caída se produce en los meses de abril y mayo, lo que refleja simplemente un diferente ritmo en la absición de las hojas en diferentes especies perennifolias. Para definir qué especies son determinantes en cada caso habría que hacer un estudio de segregación de los componentes de la hojarasca para ambos tipos de bosque.

Los valores de materia seca producidos por este bosque (3.61 ton/ha/año) son bajos, pero están en concordancia con aquellos determinados para los bosques templado-fríos del hemisferio norte, para los que se estima un valor promedio de 3.5 ton/ha/ año (Bray y Gorham, 1964). Entre los valores conocidos para bosques chilenos, son inferiores a todos, menos a los de bosques de Alerce de la Cordillera de la Costa, que presentan un valor promedio de 3.27 ton/ha/año (Donoso, 1993a).

Variación interanual y periodicidad. La tendencia a la periodicidad definida por un año de buena producción seguido por uno de mala producción de semillas en $A$. punctatum parece ser un ritmo propio de la especie, independientemente de su distribución o del hábitat en que se encuentre. Efectivamente, el mismo ritmo encuentran Murúa y González (1985) en un bosque de tierras bajas en las cercanías del Río Cruces, cerca de Valdivia, en que $A$. punctatum es una especie dominante en un tipo de bosque que constituye una transición entre los bosques con $N$. obliqua de la depresión central y los bosques siempreverdes de la ladera oriental de la Cordillera de la Costa de Valdivia. En cuatro años de evaluación en estos bosques se encuentran en forma alternada dos años con altas producciones de 606.847 y 594.453 semillas/ha y dos con bajas de 169.943 y 53.484 semillas/ha.

En las demás especies del bosque siempreverde se captan sólo ligeras tendencias que necesitan muchos más años de información para perfilarse con claridad. Las variaciones de los factores del clima, precipitación y temperatura no reflejan por el momento correlación alguna con las fluctuaciones en la producción de semillas encontradas en las especies.

\section{AGRADECIMIENTOS}

Este trabajo ha sido posible gracias al auspicio y financiamiento otorgado principalmente por la Corporación Nacional Forestal a través del Convenio CONAF-UACH "Ecología y Silvicultura de los Bosques Nativos de la X Región", y por la Empresa Forestal Venecia que ha dado su apoyo cuando ha sido necesario a través del Convenio Forestal Venecia-UACH "Manejo de los Bosques de Alerce". A lo largo de estos años son muchos los colaboradores de este trabajo, entre los cuales debo destacar y agradecer especialmente a don Anselmo Ojeda de la localidad de Hueycolla por su permanente y sacrificado trabajo de recolección del material mes a mes durante todos estos años, y al ingeniero forestal Conrado González F., por su importante apoyo en el procesamiento de gran parte de la información.

\section{BIBLIOGRAFIA}

ARMESTO, J., R. ROZZI, P. MIRANDA, C. SABAG. 1987. "Interacciones planta frugívoro en bosques templados de Sudamérica", Revista Chilena de Historia Natural 60: 321 336.

BAKER, F. S. 1950. Principies of silviculture. Mc Graw-Hill Book Company Inc., New York.

BECKER, J. 1981. Estudio de producción de litter en bosques latifoliados del sur de Chile. Tesis Fac. de Ign. Forestal, Univ. Austral de Chile, Valdivia.

BOTTI, C. y A. CABELLO, 1984. "Estudio morfoanatómico de flores, frutos y semillas de Drimys winteri Forst. (Canelo)", Ciencias Forestales 5 (1): 31-42.

BRAY, J. R. y E. GORHAM. 1964. Litter production in forests of the world. En: J. B. CREGG (ed.). Advances in Ecological Research. Vol. 2. Academic Press, New York.

BURSCHEL, P., C. GALlEGOS, O. MARTINEZ y W. MOLL. 1976. "Composición y dinámica regenerativa de un bosque virgen mixto de Raulí y Coigüe", Bosque 1 (2): 55-74.

DANIEL, T., J. HELMS y F.S. BAKER. 1982. Principios de silvicultura. Mc Graw-Hill Company Inc., México.

DONOSO, C. 1989. Tipos forestales de los bosques nativos de Chile. Documento de trabajo $\mathrm{N}^{\circ} 38$. Investigación y Desarrollo Forestal (CONAF-PNUD-FAO), Publicación FAOChile.

DONOSO, C. 1989. "Antecedentes básicos para la silvicultura del tipo forestal siempreverde", Bosque 10 (1): 37-53.

DONOSO, C. 1993a. "Producción de semilla y hojarasca en Alerce (Fitzroya cupressoides) de la Cordillera de la Costa de Valdivia". Revista Chilena de Historia Natural 66: 5364.

DONOSO, C. 1993b. Bosques templados de Chile y Argentina. Variación, estructura y dinámica. Ecología Forestal. Editorial Universitaria, $484 \mathrm{pp}$.

DONOSO, C. y A. CABELlO, 1978. "Antecedentes fenológicos y de germinación de especies leñosas chilenas", Ciencias Forestales 1 (2): 31-41.

FERNANDEZ, J. A. 1985. Propagación vegetativa $y$ germinativa de Drimys winteri J.R. et Forster. Tesis. Fac. Ciencias Forestales, Universidad Austral de Chile. 
FUENZALIDA, E. 1950a) Clima. En: Geografía Económica de Chile - Tomo I. Corporación de Fomento de la Producción. Editorial Universitaria. Santiago, Chile.

GUTIERREZ, R. 1984. Estudio comparativo de la redistribución de la precipitación entre rodales de los tipos forestales Siempreverde y Alerce. Tesis. Facultad de Ciencias Forestales, Univ. Austral de Chile, Valdivia.

HARTMANN, H. T. y D.E. KESTER. 1975. Plant propagation. Principies and practices. Third edition, Prentice Hall Inc., New Jersey.

KOSLOWSKY, T.T. 1971. Growth and development of trees. Vol. II. Cambial growth, root growth and reproduction growth. Academic Press, New York.

KRUGMAN, S.L., W. I. STEIN y D. M. SCHMIDT. 1974. Seed Biology. En: C.S. SCHOPMEYR (ed.). Seeds of Woody Plants in the United States. U.S.D.A. Handbook 450: 5-40.

MASCAREÑO, A.S. 1987. Evaluación de ensayos de semillación y regeneración de Nothofagus pumilio bajo diferentes tratamientos a la cama de semillas en Coyhaique, XI Región de Chile. Tesis, Facultad de Ciencias Forestales, Univ. Austral de Chile, Valdivia.
MURUA, R. y A. GONZA LEZ, 1985. "Producción de semillas de especies arbóreas en la pluviselva valdiviana", Bosque 6: 15-23.

NEWBOLD, P. J. 1967. Methods for Estimating the primary production of forests. IBP Handbook $\mathrm{N}^{\circ} 2$. Blackwell Scientific Publications, Oxford and Edinburg.

PUENTE, M. 1980. Estimación del mantillo acumulado en el suelo de un bosque de Hualo (Nothofagus glauca). Boletín Técnico $\mathrm{N}^{\circ}$ 5, Facultad de Ciencias Forestales, Univ. de Chile.

RIVEROS, M. y M. ALBERDI. 1978. "Acumulación de hojarasca en un bosque de Olivillo (Aextoxicon punctatum) del Fundo San Martín (Valdivia-Chile)", Bosque 2: 72-82.

RUIZ, C. 1965. Geología y yacimientos metalíferos de Chile. Instituto de Investigaciones Geológicas, Editorial Universitaria, Santiago, Chile.

U.S. Department of Agriculture, Forest Service 1974. Seeds of woody plants in the United States, U.S. Dep. Agric. Handb. 450. $883 \mathrm{pp}$. 